

\section{DISCLAIMER}

This report was prepared as an account of work sponsored by an agency of the United States Government. Neither the United States Government nor any agency Thereof, nor any of their employees, makes any warranty, express or implied, or assumes any legal liability or responsibility for the accuracy, completeness, or usefulness of any information, apparatus, product, or process disclosed, or represents that its use would not infringe privately owned rights. Reference herein to any specific commercial product, process, or service by trade name, trademark, manufacturer, or otherwise does not necessarily constitute or imply its endorsement, recommendation, or favoring by the United States Government or any agency thereof. The views and opinions of authors expressed herein do not necessarily state or reflect those of the United States Government or any agency thereof. 


\section{DISCLAIMER}

Portions of this document may be illegible in electronic image products. Images are produced from the best available original document. 


\section{LEGAL NOTICE}

This report was prepared as an account of Government sponsored work. Neither the United States, nor the Atomic Energy Commission, nor any person acting on behalf of the Commission:

A. Makes any warranty or representation, expressed or implied, with respect to the accuracy, completeness, or usefulness of the information contained in this report, or that the use of any information, apparatus, method, or process disclosed in this report may not infringe privately owned rights; or

B. Assumes any liabilities with respect to the use of, or for damages resulting from the use of any information, apparatus, method, or process disclosed in this report.

As used in the above, "person acting on behalf of the Commission" includes any employee or contractor of the Commission, or employee of such contractor, to the extent that such employee or contractor of the Commission, or employee of such contractor prepares, disseminates, or provides access to, any information pursuant to his employment or contract with the Commission, or his employment with such contractor.

Printed in the United States of America Available from

Clearinghouse for Federal Scientific and Technical Information National Bureau of Standards, U. S. Department of Commerce Springfield, Virginia 22151

Price: Printed Copy $\$ 3.00$; Microfiche $\$ 0.65$ 


\section{A FORTRAN IV PROGRAM FOR ELLIPSOMETER MEASUREMENTS OF SURFACE FILMS}

Robert W. Loser

Donald T. Larson

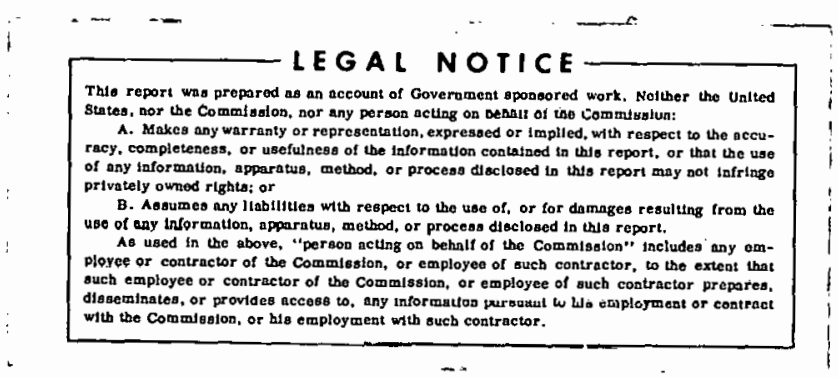

\section{THE DOW CHEMICAL COMPANY ROCKY FLATS DIVISION \\ P. O. BOX 888 \\ GOLDEN, COLORADO 80401}

Prepared under Contract AT(29-1)-1106

for the

Albuquerque Operations Office

U. S. Atomic Energy Commission 
RFP-1392 


\section{CONTENTS}

Abstract $\ldots \ldots \ldots \ldots \ldots \ldots \ldots \ldots \ldots$

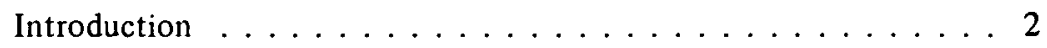

Mathematical Methods ................. 2

1. Computing the Index of Refraction

of the Substrate Material ................ 2

2. Computing the Thickness of a

Surface Film .................. 2

3. Determining the Index of Refraction

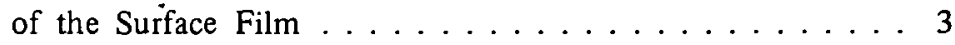

Program Description ................ 5

1. Computing the Index of Refraction

of the Substrate Material ............... 5

3. Computing the Thickness of a

Surface Film ............... 7

3. Determining the Index of Refraction of

the Surface Film and Computing Film

Thickness ................. 8

4. Calculating the Psi and Delta

Optical Parameters . . . . . . . . . . . . . . 13

Appendix A - Print-Out of the Source Program . . . . . 17

Appendix B - FORTRAN IV Notation . . . . . . . . 33 
RFP-1 392 


\title{
A FORTRAN IV PROGRAM FOR ELLIPSOMETER MEASUREMENTS OF SURFACE FILMS
}

\author{
R. W. Loser and D. T. Larson
}

\begin{abstract}
A FORTRAN IV program is presented for use with an ellipsometer to determine the index of refraction of a surface film, the thicknesses of the surface film and the index of refraction of the substrate material. The program processes data taken by an ellipsometer which is used to measure the growth of a surface film. The ellipsometer measurements are described as input data, and refractive index and film thicknesses are described as output data. Included is a brief description of the techniques used to determine refractive index and surface film thicknesses, and a complete description of the FORTRAN IV program.
\end{abstract}

\section{INTRODUCTION}

This report describes a FORTRAN IV program which is used to analyze ellipsometer data. Ellipsometry is a useful tool to study the oxidation of metals by measuring the index of refraction and thickness of the oxide film. ${ }^{(1,2)}$ The determination of the refractive index and thicknesses of the oxide film, however, is a complicated and tedious procedure. The analysis of the ellipsometer measurements therefore requires a computer. A FORTRAN IV program was written to determine the index of refraction of an oxide film, the thicknesses of the oxide film, and the index of refraction of the substrate material.

The ellipsometer measures two optical parameters, psi $(\psi)$ and delta $(\Delta)$. Psi is defined as the angle whose tangent is the amplitude ratio of the parallel and perpendicular components to the plane of incidence of the electric field vector, and delta is the phase change of these component.s. ${ }^{(3)}$ Psi and delta are related to the index of refraction of the substrate, the index of refraction of a film on the substrate, and the thickness of the film. ${ }^{(4)}$

(1) E. Passaglia, $\vec{R}$. R. Stiunlur's, and J. Yruger, Editors. Ellipsometry in the Measurement of Surfaces and Thin Films. Miscellaneous Publication 256. U.S. Department of Commerce, National Bureau of Standards, Wash. D.C., riv61.

(2) J. Kruger, Corrosion, 22, 88 (1966).

(3) R. J. Archer, J. Opt. Soc. Amer., 52, 970 (1962).

(4) F. L. McCrackin, E. Passaglia, R. K. Strombery, and H. L. Steinberg, J. Res. Natl. Bur. Std., 67A, 363 (1963).
Before the index of refraction and the thickness of a surface film can be determined, the index of refraction of the substrate must be calculated. The calculations are straightforward. Ellipsometric measurements of psi and delta are taken for a "clean" surface (subsstrate with no surface film). The values of psi and delta are then substituted into the appropriate equations to calculate the index of refraction of the substrate. ${ }^{(4)}$

The calculations for the index of refraction and thicknesses of a surface film are not straightforward. There are three unknown properties of the film to determine [the real and imaginary parts of the complex index of refraction of the film $\left(\hat{n}_{2}=n_{2}-k_{2} i\right)$, and the film thickness $\left(d_{2}\right)$ ] from only two ellipsometric measurements (psi and delta). There are two different methods for determining these properties of the surface film.

The first method is a graphical technique. ${ }^{(3,5)}$ Ellipsometric measurements of psi and delta are taken for a sample with changing film thickness. A constant index of refraction is assumed. An experimental delta-versus-psi curve is drawn from these data. Then a family of theoretical delta-versus-psi curves are drawn by calculating psi and delta points with a computer using various values for the index of refraction of the surface film over a specified film thickness range. By matching the experimental curve with one of the theoretical curves, the index of refraction of the film and the thicknesses of the film can be determined. A computer program was previously written for the theoretical calculation of psi and delta, given the values for the index of refraction of the substrate and the index of refraction and thicknesses of the surface film. ${ }^{(6)}$

In the second method (McCrackin and Colson) ${ }^{(1)}$ the best index of refraction of the surface film is selected by determining which refractive index gives the smallest

(5) D. T. Larson and N. W. Taylur, "Ellipsometry Studies on the Cleaning and Oxidation of Uranium," RFP-674, Rocky Flats Division, The Dow Chemical Co. June 1966.

(6) C. A. Larson, "FORTRAN 11 Computer Program for Analysis of Ellipsometry Data," RFP-729, Rocky Flats Division, The Dow Chemical Co., December 1966. 


\section{RFP-1392}

error in a series of experimental ellipsometric measurements (psi and delta), made on a film with changing thickness and the same refractive index. Film thicknesses are then calculated directly from the index of refraction of the substrate and the index of refraction of the surface film selected.

The general method of McCrackin and Colson ${ }^{(7)}$ was followed in writing the FORTRAN IV program to determine the index of refraction of the surface film and to calculate directly from the psi and delta measurements the thicknesses of the surface film. The FORTRAN IV program was written because major modifications of the McCrackin and Colson program would have been required for use on an IBM S/360-40 computer.

The FORTRAN IV program presented in this report is in four separate parts. The program:

1. Calculates the index of refraction of the substrate material.

2. Calculates the thickness of a surface film for each psi and delta measurement given the index of refraction of the substrate material and the index of refraction of the surface film.

3. Determines the index of refraction of the surface film from a given series of psi and delta measurements, then calculates film thicknesses using the index of refraction of the surface film selected and the index of refraction of the substrate material.

4. Calculates the psi and delta optical parameters given the index of refraction of the suhstrate material, tho index of refraction of the surface film and the thicknesses of the film.

\section{MATHEMATICAL METHODS}

1. Computing the Index of Refraction of the Substrate Material

The index of refraction of the substrate material is given by $\hat{n}_{3}=n_{31}-n_{32} i$, where $n_{31}$ is the real part of the refractive index and $n_{32}$ is the imaginary part. The calculations for $n_{31}$ and $n_{32}$ are based upon:

(7) F. L. McCrackin and J, P. Colson, "A FORTRAN Program for Analysis of Ellipsometer Measurements and Calculations of Reflection Coefficients from Thin Films," Technical Note 242, U.S. Dept. of Commerce, Nat'l Bureau of Stds., Wash. D.C., 1964. a. The index of refraction of the surrounding medium.

b. The angle of incidence.

c. The psi and delta measurements made on a clean substrate surface.

The equations used to calculate $n_{3 i}$ and $n_{32}$ are given by Vasicek. (1)

\section{Computing the Thickness of a Surface Film}

The thickness of a surface film can be computed using the fundamental ellipsometric equation and the exact Diude equations (Mclrackin and Colsnn) ${ }^{(1)}$. The oulcu: lations are based upon:

a. The index of refraction of the surrounding medium.

b. The angle of incidence.

c. the wavelength of the light beam.

d. The index of refraction of the substrate.

e. The index of refraction of the surface film.

f. The experimental psi and delta measurements.

The index of refraction of the substiale is given by $\widehat{n}_{3}=n_{31}-n_{32} i$. The index of refraction of the surface film is given by $\hat{n}_{2}=n_{2}-n_{2} i$. The thickness of the surface film is given by $d_{2}$. The following equations are used by the computer to calculate $\mathrm{d}_{2}$.

$$
\begin{aligned}
& \ddot{R}_{n}=\frac{\hat{r}_{12}^{n}+\hat{r}_{23}^{n} e^{\hat{s}}}{1+\hat{r}_{12}^{n} \hat{r}_{23}^{n} e^{\hat{s}}} \\
& \hat{R}_{p}=\frac{\hat{r}_{12}^{p}+\hat{r}_{23}^{p} e^{\hat{s}}}{1+\hat{r}_{12}^{p} \hat{r}_{23}^{p} e^{\hat{\theta}}} \\
& \hat{s}^{p}=\frac{-4 \pi i}{\lambda} \cdot \hat{n}_{2} \cos \hat{\phi}_{2} d_{2} \\
& \frac{\hat{R}_{p}}{\hat{R}_{n}^{n}}=T_{a n} \psi e^{i} \Delta \\
& \hat{r}_{12}^{n}=\frac{n_{1} \cos \phi_{1}-\hat{n}_{2} \cos \hat{\phi}_{2}}{n_{1} \cos \phi_{1}+\hat{n}_{2} \cos \hat{\phi}_{2}}
\end{aligned}
$$


$\hat{r}_{23}{ }^{n}=\frac{\hat{n}_{2} \cos \hat{\phi}_{2}-\hat{n}_{3} \cos \hat{\phi}_{3}}{\hat{n}_{2} \cos \hat{\phi}_{2}+\hat{n}_{3} \cos \hat{\phi}_{3}}$

$\hat{r}_{12}^{p}=\frac{\hat{n}_{2} \cos \phi_{1}-n_{1} \cos \hat{\phi}_{2}}{\hat{n}_{2} \cos \phi_{1}+n_{1} \cos \hat{\phi}_{2}}$

$\hat{r}_{23}^{p}=\frac{\hat{n}_{3} \cos \hat{\phi}_{2}-\hat{n}_{2} \cos \hat{\phi}_{3}}{\hat{n}_{3} \cos \hat{\phi}_{2}+\hat{n}_{2} \cos \hat{\phi}_{3}}$

$\cos ^{2} \hat{\phi}_{2}=1-\frac{\mathrm{n}_{1}{ }^{2} \sin ^{2} \phi_{1}}{\hat{n}_{2}{ }^{2}}$

$\cos ^{2} \hat{\phi}_{3}=1-\frac{n_{1}{ }^{2} \sin ^{2} \phi_{1}}{\hat{n}_{3}{ }^{2}}$

$n_{1}=$ index of refraction of the surrounding medium.

$\phi_{1}=$ angle of incidence.

$\lambda=$ wavelength of the light beam.

$\hat{n}_{3}=$ index of refraction of the substrate.

$\hat{n}_{2}=$ index of refraction of the surface film.

$d_{2}-$ thickness of the surface film.

$\left.\begin{array}{l}\psi \\ \Delta\end{array}\right\}=$ the experimental ellipsometric mcasurcments.

Equation 2.1 and equation 2.2 are the exact Drude equations. Equation 2.4 is the fundamental ellipsometric equation. Equations 2.5 through 2.8 are the Fresnel reflection coefficients, and equation 2.9 and equation 2.10 were derived from Snell's Law.

Following the method of McCracking and Colson, ${ }^{(1)}$ a complex quadratic equation is obtained of the form

$$
\hat{A} c^{2 \hat{S}}+\hat{B} e^{\hat{s}}+\hat{C}=0
$$

by using equations $2.1,2.2$, and 2.4 . Solving the quadratic equation for $\mathrm{e}^{\mathrm{s}}$ and separating the real and imaginary terms, equation 2.11 reduces to the general form

$$
e^{\hat{s}}=x+y i=\sqrt{\dot{x}^{2}+y^{2}} e^{i(\phi+2 n \pi)}
$$

where $\phi=\operatorname{Tan}^{-1} y / x$ and

$$
\mathrm{n}=0, \pm 1, \pm 2, \cdots \text {. }
$$

Taking the natural logarithm of both sides of equation 2.12. results in the equation

$$
\hat{s}=\ln \sqrt{x^{2}+y^{2}}+i(\phi+2 n \pi)
$$

By equating equation 2.14 with equation 2.3 , a complex equation for film thickness $\left(d_{2}\right)$ can be obtained. There are two solutions for $d_{2}$ arising from the quadratic equation. The correct solution is chosen by selecting the value of $d_{2}$ with the smallest imaginary part. The real part is used as the thickness of the surface film.

3. Determining the Index of Refraction of the Surface Film

The index of refraction of the surface film is given by $\hat{n}_{2}=n_{21}-n_{22} i$. The index of refraction is determined by first assuming a range of values for $n_{22}$. Then for a psi and delta measurement, a value of $n_{22}$ is used with an iteration process to find a value for $\mathrm{n}_{21}$ which minimizes the imaginary part of film thickness. The process is repeated for all the psi and delta measurements in a set of data. The standard error* for the calculated $n_{21}$ values is determined. The whole process is then repeated for the entire range assumed for $n_{22}$. The value of $n_{22}$ which minimizes the standard error for $n_{21}$ is selected as the imaginary part of $\hat{n}_{2}$ and the corresponding mean of the $\mathrm{n}_{21}$ calculations is selected as the real part of $\hat{n}_{2}$.

The iteration process for finding $\mathrm{n}_{21}$ is as folluws. A range for $n_{21}$ must be given and tested to determine if a solution for $n_{21}$ exists in the given range. This is done by making film thickness calculations for a psi and delta ellipsometric measurement using the minimum and maximum values of the $n_{21}$. range and the assumed value for $n_{22}$. The film thicknesses are, in general, complex. The signs of the two imaginary parts (minimum and maximum values of $\mathrm{n}_{21}$ ) are compared. If the signs are the same, the range is too large or too small for a solution. If no solution exists, the next psi and delta measurement is processed. If the signs are opposite, there is a solution within the $n_{21}$ range. To illustrate this point, a graph of the imaginary film thickness calculated for various values of $n_{21}$ using $\psi=30.70^{\circ}$,

$$
\mathrm{S}_{\overline{\mathrm{v}}}=\sqrt{\frac{\Sigma\left(\mathrm{X}_{\mathrm{i}}-\overline{\mathrm{X}}\right)^{2}}{\mathrm{n}(\mathrm{n}-1)}}
$$


$\Delta=114.15^{\circ}$, and $\mathrm{n}_{22}=1.5$ is presented in Figure 1. The values of psi and delta were caluclated using $n_{3}=3.2-4.3 \mathrm{i}$, $\hat{n}_{2}=2.0-1.5 \mathrm{i}$ and $\mathrm{d}_{2}=100 \AA$.

Figure 2 shows the results using $\psi=19.93^{\circ}, \Delta=85.15^{\circ}$, and $n_{22}=1.5$. These values for psi and delta were calculated using $d_{2}=1000 \AA$. Note that in Figure 2, a second solution for $\mathrm{n}_{21}$ can be obtained, e.g., by specifying the $n_{21}$ range to be $2.2-2.8$. For the case where more than one solution exists, the currect solution will be the one having the maximum number of $n_{21}$ values calculated for the set of psi and delta measurements.

A solution for $\mathrm{n}_{21}$ is desired which makes the imaginary part of film thickness approach zero. This can be conveniently done by calculating and comparing error terms tor various. values of $n_{2}$. An error term is determined by taking the film thickness calculated for the $n_{21}$ value, and using the real part to calculate psi and delta. The error term is defined by the equation

$$
\epsilon=\sqrt{(\delta \psi)^{2}+(\delta \Delta)^{2}}
$$

$$
\text { where } \begin{aligned}
\delta \psi & =\psi \text { experimental }-\psi \text { calculated and } \\
\delta \Delta & =\Delta \text { experimental }-\Delta \text { calculated }
\end{aligned}
$$

This error criteria is used rather than the value of the imaginary part of the film thickness since $\epsilon$ relates directly to the quantities obtained from the ellipsometer and is thcrcforc yuantitatively more meaningful to the experiment. Upon testing for a solution for $n_{21}$, an error term is calculated at the midpoint of the $n_{21}$ range. The half of the $n_{21}$ range which contains the solution for $\mathrm{n}_{21}$ (as determined by the segment giving opposite signs of the imaginary part of film thickness) is selected. The half selected is again divided in half and another film thickness and error term are calculated. This process is repeated until a minimum error term is found.

A tolerance level can be used to aid the iteration process. Once the error term calculated is within the tolerance level specified, the iteration process for $n_{21}$ teminates. The Iteration process is limited by a given number of cycles. If a minimum error term or an error term within the tolerance level cannot be found within the number of cycles specified, a no solution criterion will be printed out by the computer.

Upon determining the index of refraction of the surface film, film thicknesses are computed for each of the psi and delta measurements.

FIGURE 1. Imaginary Film Thickness - versus $-\mathrm{n}_{21}$ for $\mathrm{Psi}=30.70^{\circ}$ and Delta $=114.15^{\circ}$ for the Following Paraneters: $n_{1}=1.00, \phi_{1}=70^{\circ}, \lambda=5461 A^{\circ}, \hat{n}_{3}=3.2-4.3 i$ and $\hat{n}_{2}=n_{21}-1.5 i$.

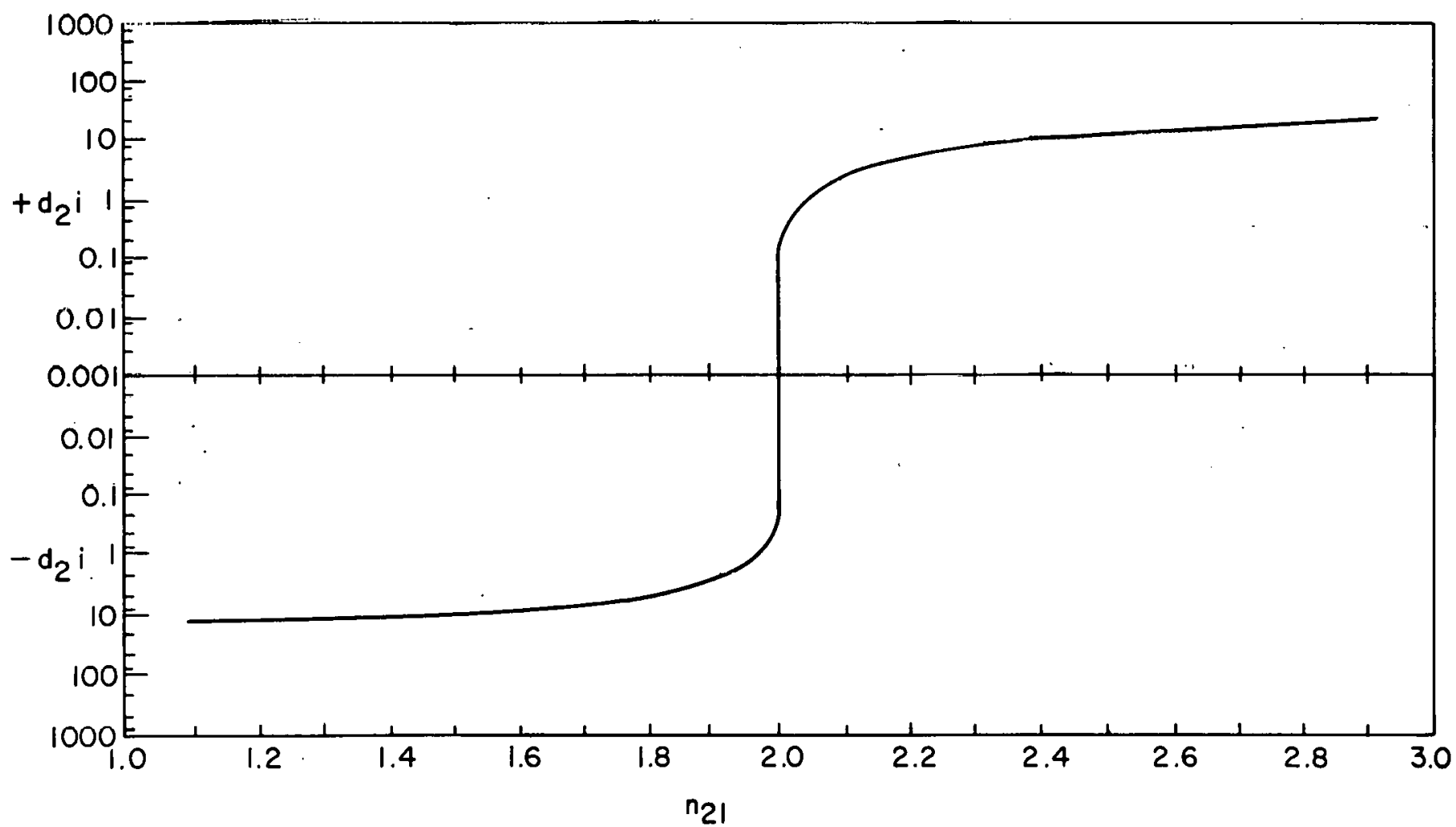




\section{PROGRAM DESCRIPTION}

The source program deck consists of a main program and seven subroutine subprograms (707 executable and non-executable statements, 798 cards). The memory requirements of the main program total 13,854 bytes and the memory requirements of the subroutine subprograms total 11,220 hytes. The source program deck can be compiled in four minutes and link edited in two minutes in an IBM $S / 360-40$ computer. The execution time can be estimated from the number of psi and delta measurements processed. Film thicknesses are calculated and printed out in 0.4 second per psi, delta measurement. A line-printer output device with not less than 120 columns per line is sufficient for a print-out of results. A print-out of the source program is shown in Appendix $A$ and an explanation of the FORTRAN IV notation is shown in Appendix B.

The source program consists of four parts, the computation and print-out of the index of refraction of the substrate material, the computation and print-out of the thicknesses of the surface tilm, the determination of the index of refraction of the surface film followed by film thickness calculations, and the computation and printout of the psi and delta optical parameters. Access to each part is controlled by the variable name IPICK as shown in Figure 3. Any or all of the four parts can be processed per run.

1. Computing the Index of Refraction of the Substrate Material

The index of refraction of the substrate material, $\hat{n}_{3}=n_{31}-n_{32} i$, is calculated by the subroutine subprogram EN3. The calculations are direct and require:

a. The index of refraction of the surrounding medium,

b. The angle of incidence.

c. The psi $\left(\psi^{\prime}\right)$ and delta $\left(\Delta^{\prime}\right)$ measurements of the substrate material.

FIGURE 2. Imaginary Film Thickness - versus $-\mathrm{n}_{21}$ for $P s i=19.93^{\circ}$ and Delta $=85.15^{\circ}$ for the

Following Parameters: $\mathrm{n}_{1}=1.00, \phi_{1}=70^{\circ}, \lambda=5461 \mathrm{~A}^{\circ}, \hat{\mathrm{n}}_{3}=3.2-4.3 \mathrm{i}$ and $\hat{\mathrm{n}}_{2}=\mathrm{n}_{21}-1.5 \mathrm{i}$.

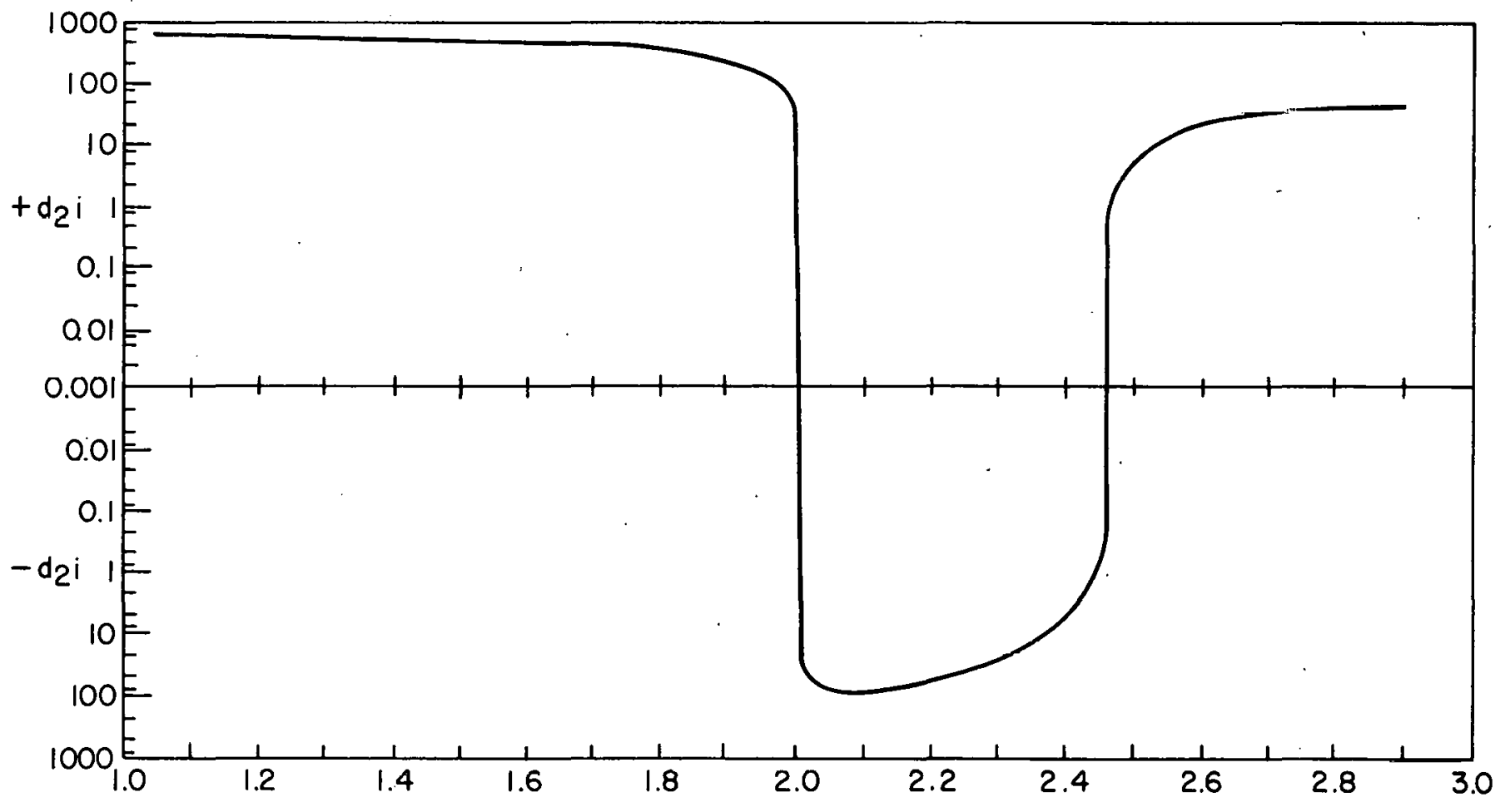

$n_{21}$ 


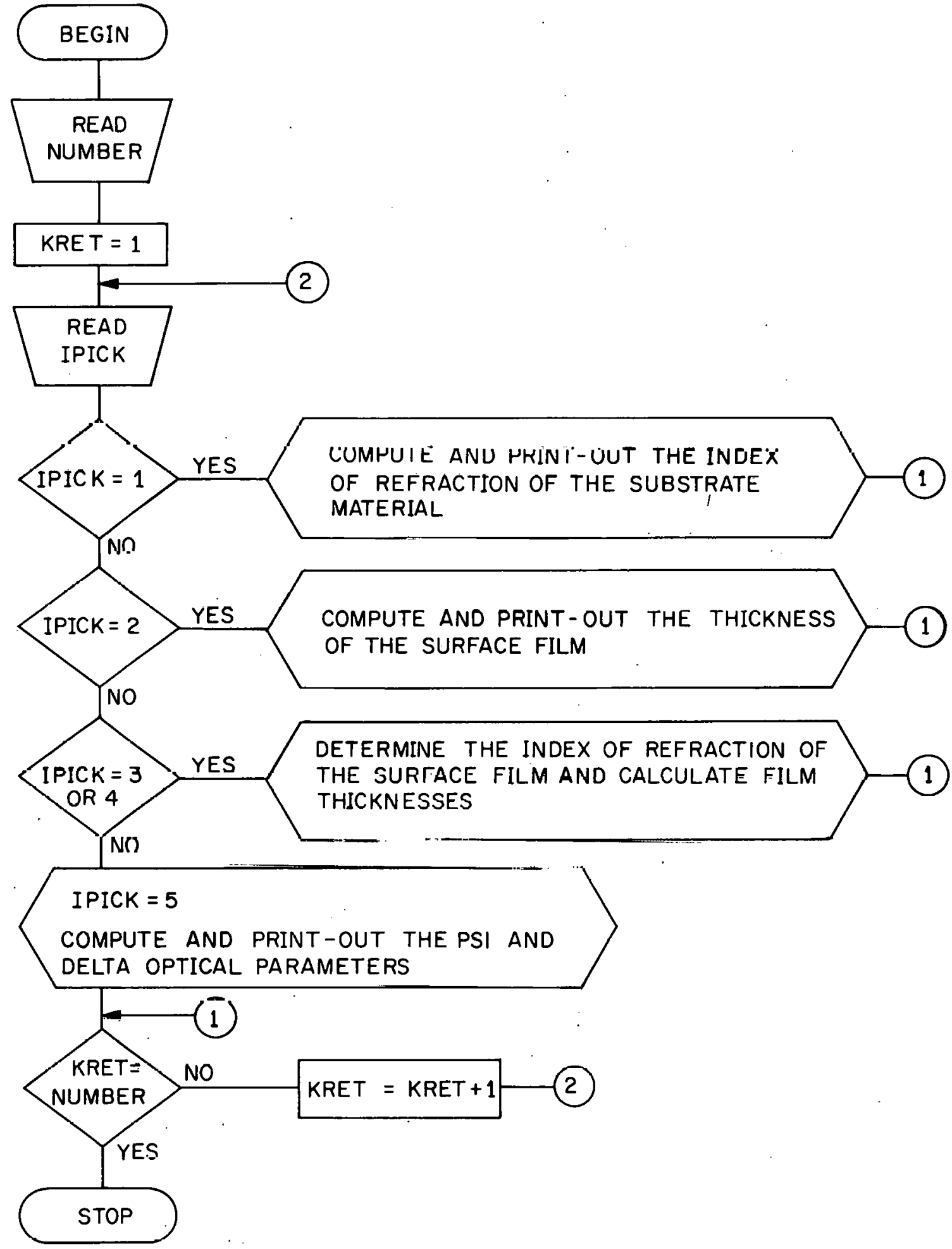

FIGURE 3. Flowchart showing the Four Parts of the Source Program. 
The input data can be punched into cards for a card read-punch input-output device. The data set has a title card and up to twenty measurements of psi and delta can be processed per run. Figure 4 shows the field format layout and gives a description of each of the cards.

The output data consist of the $n_{31}$ and $n_{32}$ values as shown in Figure 5.

\section{Computing the Thickness of a Surface Film}

The thickness of a surface film is calculated by the subroutine subprogram RID2. The calculations are direct and require:

a. The index of refraction of the surrounding medium.

b. The angle of incidence.

c. The wavelength of the light beam.

d. The index of refraction of the substrate. e. The index of refraction of the surface film.

f. The experimental psi and delta measurements.

Part 2 of the program is useful when both the index of refraction of the substrate and the index of refraction of the surface film are known. The input data can be punched into cards for a card read-punch input-output device. The data set has a title card and up to thirty measurements of psi and delta can be processed per run. Figure 6 shows the field format layout and gives a description of each of the cards. The input data were obtained from F. L. McCrackin, Washington, D.C. in a private communication.

The growth of a surface film as measured by an ellipsometer can be described via the cycling of the angle phi $(\phi)$ in a rectilinear coordinate system. Phi is defined by equations 2.12 and 2.13 .

$$
\begin{aligned}
& \mathrm{e}^{\hat{s}}=\mathrm{x}+\mathrm{yi}=\sqrt{\mathrm{x}^{2}+\mathrm{y}^{2}} \mathrm{e}^{\mathrm{i}(\phi+2 \mathrm{n} \pi)} \\
& \phi=\operatorname{Tan}^{-1} \mathrm{y} / \mathrm{x} \\
& \mathrm{n}=0, \pm 1, \pm 2,
\end{aligned}
$$

FIGURE 4. Field Format Layout and Card Description of the Input Data for Part 1 of the Source Program.

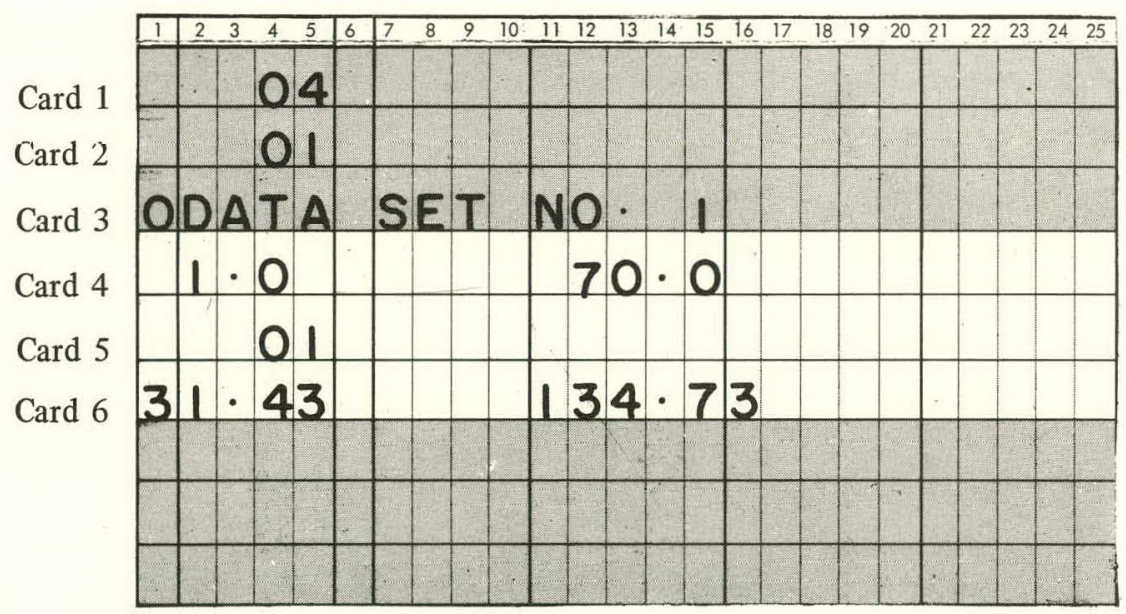

Card 1 - The total number of data sets in the card deck.

Card 2 - The value of IPICK.

Card 3 - The title card (column 1 reserved for the digit 0 for carriage control).

Card 4-The index of refraction of the surrounding medium and the angle of incidence in two 10 column fields, respectively.

Card 5 - The number of psi and delta measurements.

Card 6 - The psi and delta measurements in two 10-column fields, respectively, per card. 
For an experimental set of psi and delta measurements of increasing film thickness, the angle phi cycles clockwise through the quadrants. To obtain the correct solution for film thickness $d_{2}$, the value of $n$ in equation 2.12 is -1 for the first cycle, -2 for the second cycle, etc. The growth of the film can be monitored by the computer by determining which quadrant phi is in from the values of $\mathrm{x}$ and $\mathrm{y}$.

The subroutine subprogram QTEST2 determines the quadrant for the angle phi, corrects for the case where phi should fall in Quadrant III or Quadrant II,* and corrects for the complete cycling of phi. The subroutine subprogram QTEST is also used but strictly for placing phi in Quadrant III or Quadrant II.

The output data consist of the thickness of the surface film, the error term $\epsilon$ and the quadrant of the angle phi for each of the psi and delta measurements. 'l'he results of the test data are shown in Figure 7. The values of psi and delta for the film thicknesses from 0 to $1000 \AA$ in $100 \AA$ increments were calculated using the following parameters:

$$
\begin{aligned}
& \mathrm{nl}_{1}=1.0 \\
& \phi_{1}=70^{\circ} \\
& \lambda=5461 \AA \\
& \hat{\mathrm{n}}_{3}=3.2-4.3 \mathrm{i} \\
& \hat{\mathrm{n}}_{2}=2.0-1.5 \mathrm{i}
\end{aligned}
$$

The calculated values for psi and delta were then rounded off to the second decimal place before being used in the calculations. Thus, small round-off errors will appear in the film thicknesses shown.

\footnotetext{
"'The FUR'IRAN IV compiler will place phi in Quadrant I for the arctangent of a positive argument and in Quadrant IV for the arctangent of a negative argument.
}

3. Determining the Index of Refraction of the Surface Film and Computing Film Thickness

The index of refraction of the surface film, $\hat{n}_{2}=n_{21}-n_{22} \mathrm{i}$, is determined by the main program and the subroutine subprogram RID2. The main program calls in values of $n_{22}$, controls the iteration process for $n_{21}$, computes the error terms, and finally selects $n_{21}$ and $\mathrm{n}_{22}$ for the index of refraction of the surface film. The subroutine subprogram RID2 calculates film thicknesses and values of psi and delta. The subroutine subprograms QTEST and QTEST3 correct and control the cycling of the angle phi. The latter subroutine subprogram is used especially for both the minimum and maximum values of the $n_{21}$ range. The subroutine subprogram QTEST4 selects the quadrant for the optical parameter, delta $(\Delta)$, and the subroutine subprogram RANGE calculates values of $\mathrm{n}_{22}$ from a given range of $\mathrm{n}_{22}$ and the increment $\Delta \mathrm{n}_{2,2}$.

In the main program, the iteration process for $n_{21}$ uses three variable names, TOL, ITOL, and NTEST. The variahle name TOI, indicates a tolerance level of error which stops the cycling for $\mathrm{n}_{21}$ once the error term $\epsilon$ is within TOL. If ITOL $=0$, the value of TOL will be ignored and the computer could cycle NTEST times for $\mathrm{n}_{21}$. If a solution is found, the error term $\epsilon$ is printed out along with the value of $n_{21}$ computed for the psi and delta measurement. If $\mathrm{n}_{21}$ can't be determined in NTEST cycles, a no solution criterion is detected by the computer and the appropriate code number is printed out.

It is recommended that a tolerance level always be used but in the case where an appropriate tolerance level is not known, the computer can be used to determine one.

FIGURE 5. Output Data Showing the Results of Part 1 of the Sourcc Program.

\section{THE INDEX OF REFRACTION OF A CLEAN SURFACE DETERMINED BY THE METHOD OF FLLIPSOMFTRY}

DATA SET NO. 1

THE INDEX UF REFRACTION OF THE SURROUNDING MEDIUM IS 1.00

THE ANGLE OF INCIDENCE IS 70.00 DEGREES
PS I PR IME
DEL PRIME
N 31
N32

1

$$
31.430
$$

134.730

$0.31999 E_{01}$

$0.43012 E \quad 01$ 
FIGURE 6. Field Format Layout and Card Description of the Input Data for Part 2 of the Source Program.

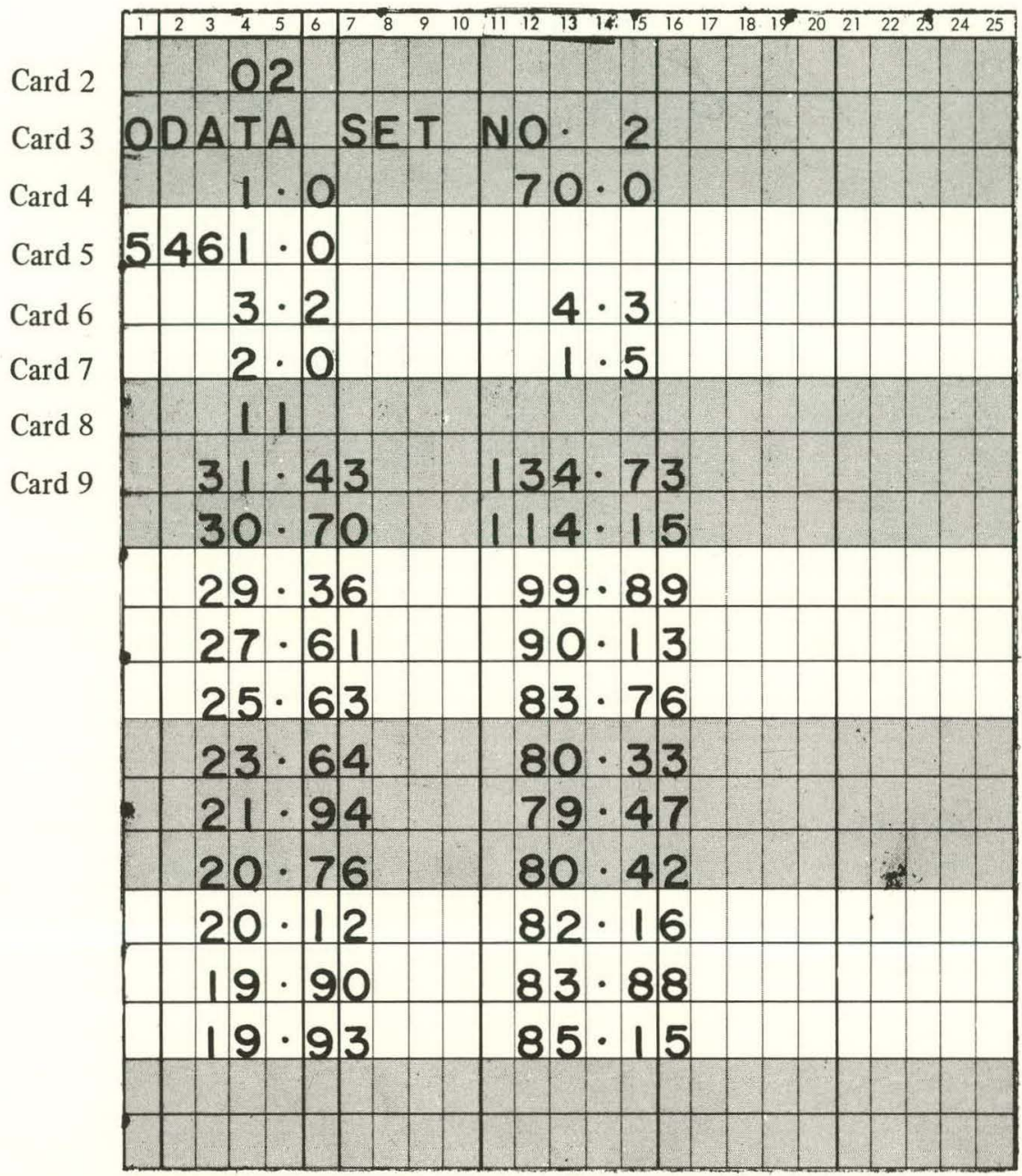

Card 2 - The value of IPICK.

Card 3 - The title card (column 1 reserved for the digit 0 for carriage control).

Card 4 - The index of refraction of the surrounding medium and the angle of incidence in two 10-column fields, respectively.

Card 5 - The wavelength of the light beam.

Card 6 - The real and imaginary parts of the refractive index of the substrate in two 10-column fields, respectively.

Card 7 - The real and imaginary parts of the refractive index of the surface film in two 10-column fields, respectively.

Card 8 - The number of psi and delta measurements.

Cards 9-19 - The psi and delta measurements in two 10-column fields, respectively, per card. 


\section{RFP-1392}

The input data for determining the index of refraction of the surface film consist of:

a. The index of refraction of the surrounding medium.

b. The angle of incidence.

c. The wavelength of the light beam.

d. The psi and delta measurements of the substrate material (IPICK $=3$ ) or the real and imaginary parts of the refractive index of the substrate (IPICK=4).

e. The minimum and maximum values of the $\mathrm{n}_{22}$ range with the increment $\Delta \mathrm{n}_{22}$.

f. The minimum and maximum values of the $n_{21}$ range.

g. The experimental psi and delta measurements.

h. The tolerance level TOL for the set of data. i. The value of ITOL.

j. The value of NTEST.

The input data can be punclied intu vards for a cuad read-punch input-output device. The data set has a title card and up to thirty measurements of psi and delta can be processed per run. Thirty values of $n_{22}$ can also be processed per run. Figure 8 shows the field format layout and gives a description of each of the cards.

The output data consist of the values of $n_{21}$ for the psi and delta measurements (or no solution at all), the error terms, the code numbers depicting the results of the iteration process and the mean value of $n_{21}$ and the standard error for the set of data. A print-out will occur for each value of $n_{2}$, used. Figure 9 shows the results for $\mathrm{n}_{22}=1.5$ which gives the minimum standard error for the mean of the $\mathrm{n}_{21}$ calculations and hence, the best index of refraction of the surface film. Figure 10 shows the resulting film thicknesses for $n_{2}=2.0-1.5 i$.

FIGURE 7. Output Data Showing the Results of Part 2 of the Source Program.

\section{THE THICKNESS OF A SURFACE FILM DETERMINED BY THE METHOD OF FI I IPSOMFTRY}

DATA SET NO. 2

THE INDEX OF REFRACTION OF THE SURRDUNDING MEDIUM IS 1.00

THE ANGLE OF INCIDENCE IS 70.00 DEGREES

THE WAVELENGTH DF LIGHT IS 5461.00 ANGSTROMS

THE INDEX OF REFRACTION OF THE SUBSTRATE IS N31 \#3.20 AND N32 \#4.30

THE VALUE OF N21 IS 2.00

THE VALUE OF N22 IS 1.50

$\begin{array}{rrrrrrr} & \text { PSI } & \text { DELTA } & \text { THICKNESS } & \text { ERROR } & \text { QUADRANT } \\ 1 & 31.430 & 134.730 & -0.2117979 \mathrm{E}-01 & 0.44336 \mathrm{E}-02 & 4 \\ 2 & 30.700 & 114.150 & 0.1000021 \mathrm{E} 03 & 0.56284 \mathrm{E}-02 & 4 \\ 3 & 29.360 & 99.890 & 0.2000097 \mathrm{E} 03 & 0.15028 \mathrm{E}-03 & 4 \\ 4 & 27.610 & 90.130 & 0.3000828 \mathrm{E} 03 & 0.36629 \mathrm{E}-02 & 4 \\ 5 & 25.63 \mathrm{C} & 83.760 & 0.4000750 \mathrm{E} 03 & 0.39866 \mathrm{E}-02 & 3 \\ 6 & 23.640 & 80.330 & 0.5001167 \mathrm{E} 03 & 0.47694 \mathrm{E}-03 & 3 \\ 7 & 21.940 & 79.470 & 0.6002280 \mathrm{E} 03 & 0.35722 \mathrm{E}-02 & 3 \\ 8 & 20.16 U & 80.420 & 0.6998442 \mathrm{E} 03 & 0.25940 \mathrm{E}-02 & 3 \\ 9 & 20.120 & 82.160 & 0.7995803 \mathrm{E} 03 & 0.30755 \mathrm{E}-02 & 2 \\ 10 & 19.900 & 83.880 & 0.8998027 \mathrm{E} \mathrm{O3} & 0.21223 \mathrm{E}-02 & 2 \\ 11 & 19.930 & 85.150 & 0.9995212 \mathrm{E} \mathrm{O3} & 0.16854 \mathrm{E}-03 & 2\end{array}$


FIGURE 8. Field Format Layout and Card Description of the Input Data for Part 3 of the Source Program.

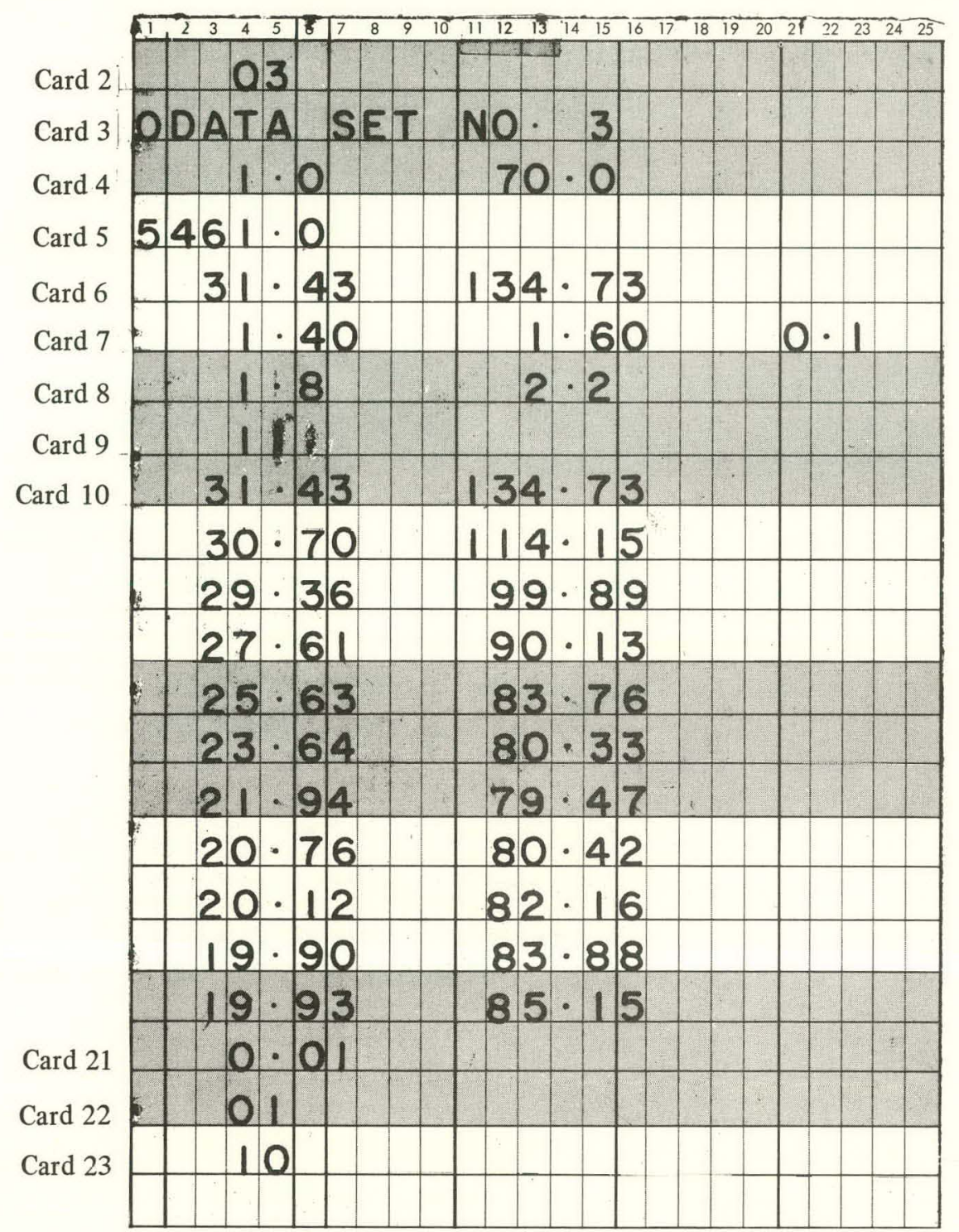

Card 2 - The value of IPICK.

Card 3 - The title card (column 1 reserved for the digit 0 for carriage control).

Card 4 - The index of refraction of the surrounding medium and the angle of incidence in two 10-column fields, respectively.

Card 5 - The wavelength of the light beam.

Card 6 - The psi and delta measurements of the substrate material in two 10-column fields, respectively.

Card 7 - The minimum and maximum values of the $\mathrm{n}_{22}$ range and $\Delta \mathrm{n}_{22}$ in three 10-column fields, respectively.

Card 8 - The minimum and maximum values of the $n_{21}$ range in two 10-column fields, respectively.

Card 9 - The number of psi and delta measurements.

Cards 10-20 - The psi and delta measurements in two 10-column fields, respectively, per card.

Card 21 - The tolerance level for the set of data.

Card 22 - The value of ITOL.

Card 23 - The value of NTEST. 
THE OPTICAL CONSTANT N21 FDR PSI AND DELTA OR NO SOLUTION AT ALL

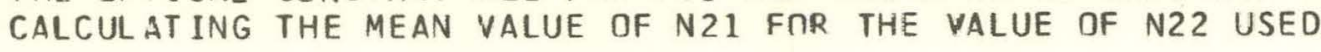

DATA SET NO. 3

THE INDEX OF REFRACTION OF THE SURROUNDING MEDIUM IS 1.00

THE ANGLE OF IN IDENCE IS 70.00 DEGREES

THE WAVELENGTH DF LIGHT IS 5461.00 ANGSTROMS

THE OPTICAL PARAMETERS OF THE SUBSTRATE ARE PSI PRIME \# 31.430 AND DEL PRIME \# 134.730

THF CALCULATFD INDEX OF REFRACTION OF THE SUBSTRATE IS N31 \# 0.31 C9.9E 01 AND N32 \#0.43012E 01

THE RANGE OF N22 IS MIN\# 1.40, MAX\# 1.60, DELTA\# 0.10

THE RANGE OF N21 IS MIN\# 3.80 , MAX\# 2.20

THE GIVEN TOLERANCE WHICH WAS EXECUTED IS $0.10000 E-01$, THE TEST VALUE IS 10

THE VALUE OF N22 IS $0.15000 E 01$

CODE 1 MEANS THE ARSOLUTF VALUE OF THE IMAGINARY THICKNESS IS LESS THAN OR EQUAL TO 0.1E-0E ANGSTROMS

CODE 3 MEANS THE GIVEN TOLERANCE WAS TOO SMALL IN SELECTING N2 1

CODE 4 MEANS THE GIVEN TOLERANCE WAS TOO LARGE IN SELECTING N21

CODE 5 MEANS THE GIVEN TOLERANCE WAS EXECUTED IN SELECTING N21

CODE 6 MEANS NO SOLUTION JUE TO LIKE SIGNS OF THE IMAGINARY PARTS OF FILM THICKNESS

CODE 7 MEANS NO SOLUTION, TOL TOO SMALL, TEST VALUE TOO SMALL, INCREAS ING ERROR IN COMPUTING N21

CODE 8 MEANS NO SOLUTION, TOL TOO SMALL. TEST VALUE TOO SMALL. DECREASING ERROR IN COMPUTING N2I

CODE 9 MEANS NO SOLUTION, TOL TOO LARGE, TEST VALUE TOO SMALL, INCREASING ERROR IN COMPUTING N21

CODE 10 MEANS NO SOLUTION. TOL TOO LARGE, TEST VALUE TOO SMALL, DECREASING FRROR IN COMPUTING N2I
PSI
DELTA
N2 1
ERROR NOT EXCEEDING CODE

$\begin{array}{rr}31.430 & 134.730 \\ 30.700 & 114.150 \\ 29.360 & 99.890 \\ 27.610 & 90.130 \\ 25.630 & 83.760 \\ 23.640 & 80.330 \\ 21.940 & 79.470 \\ 20.760 & 80.420 \\ 20.120 & 82.160 \\ 19.900 & 83.880 \\ 19.930 & 85.150\end{array}$

$0.1999999 E$ OI

$0.1999999 E$ OI

$0.1999999 \mathrm{E} \quad 01$

$0.1999999 E$ OI

$0.1999999 E$ OI

$0.24232 E-02$

$0.26917 E-02$

$0.59493 E-02$

$0.63084 E-02$

$0.26845 E-02$

$0.1999999 E$ O1

$0.1999999 \mathrm{E} \mathrm{OI}$

$0.36951 E-02$

$0.23747 E-02$

0.1999999 E 01

$0.12302 \mathrm{E}-03$

6
5
5
5
5
5
6
5
5
5
5

the MEAN VALUE CF N21 IS 0.1999999E 01, THE StANDARD ERROR FOR 8 JaLIJES OF N21 IS 0.0 


\section{Calculating the Psi and Delta Optical Parameters}

Film thicknesses can be used to calculate psi and delta. Part 4 of the source program calculates the optical parameters for the film thicknesses given for any combination of $n_{21}$ and $n_{22}$. The calculations are made by the subroutine subprogram RID2. The subroutine subprogram QTEST4 selects the quadrant for the optical parameter, delta $(\Delta)$. The subroutine subprogram

RANGE calculates values of $\mathrm{n}_{22}$ and $\mathrm{n}_{21}$ from the minimum and maximum values of each of the given ranges. The ranges are incremented by $\Delta \mathrm{n}_{22}$ and $\Delta \mathrm{n}_{21}$.

The main program consists of three DO loops. An innermust DO loop controls the given film thicknesses, a second DO loop controls the values of $\mathrm{n}_{21}$ and the third and outermost DO loop controls the values of $\mathrm{n}_{22}$. The psi and delta optical parameters can be calculated for the film thicknesses for all of the $\mathrm{n}_{21}$ values for each of the $n_{22}$ values.
The input data consist of:

a. The index of refraction of the surrounding medium.

b. The angle of incidence.

c. The wavelength of the light beam.

d. The index of refraction of the substrate.

e. The minimum and maximum values of the $n_{22}$ range with the increment $\Delta \mathrm{n}_{22}$.

f. The minimum and maximum values of the $n_{21}$ range with the increment $\Delta \mathrm{n}_{21}$.

g. The film thicknesses.

FIGURE 10. Output Data Showing the Resulting Film Thicknesses for Part 3 of the Source Program.

\begin{abstract}
THE THICKNFSS OF A SURFACE FIL Y METERMINED BY THE METHOD OF FLLI PSOMFTRY
\end{abstract}

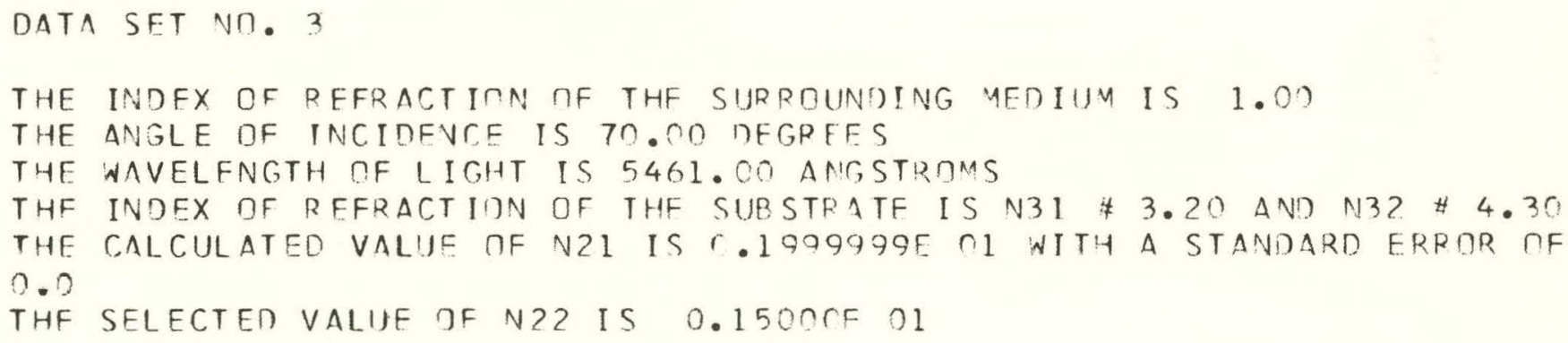

DS I

31.430
30.700
29.360
27.610
25.630
23.640
21.940
20.760
20.120
19.900
19.930

\section{DELTA}

$$
\begin{array}{r}
134.730 \\
114.150 \\
99.890 \\
90.130 \\
83.760 \\
80.330 \\
79.470 \\
80.420 \\
82.160 \\
83.390 \\
85.150
\end{array}
$$

$$
\text { THICKNESS }
$$$$
0.1980386 E-C^{3}
$$$$
0.10 \mathrm{CO} 334 \mathrm{~F} \quad \mathrm{~B}
$$$$
0.2000312 \mathrm{~F} \quad 03
$$$$
0.3001042 E \quad 3
$$$$
0.40 .00962 \mathrm{~F} \quad 3
$$$$
\text { Q. } 5 \text { Cn1365E C? }
$$$$
0.60 \mathrm{C} 2480 \mathrm{O} \quad 3
$$$$
\text { r.6998682F } 03
$$$$
0.7996038 \mathrm{~F} \quad 3
$$$$
\text { C.8998267E त3 }
$$$$
0.9995427 E \text { (3 }
$$

ERR JR

QUADRANT

$0.48253 F-04$

ก.24232F-02

$0.26917 \mathrm{~F}-0$ ?

$0.594935-02$

?.63084F-02

0.2684 Jt -02

$0.17711 F-02$

$0.37579 F-02$

$0.36951 \mathrm{~F}-02$

0. $73747 F-0$ ?

$0.12302 E-03$

1
4
4
4
3
3
3
3
2
2
2




\section{RFP-1392}

The input data can be punched into cards for a card read-punch input-output device. The data set has a title card and up to thirty values of film thickness can be processed per run. Thirty values each of $n_{22}$ and $n_{21}$ can also be processed per run. Figure 11 shows the field format layout and gives a description of each of the cards.
The output data consist of the psi and delta optical parameters. A print-out will occur for each combination of $n_{21}$ and $n_{22}$. Figure 12 shows the results for the index of refraction of the surface film $\hat{n}_{2}=2.0-1.5$ i.

FIGURE 11. Field Format Layout and Card Description of the Input Data for Part 4 of the Source Program.

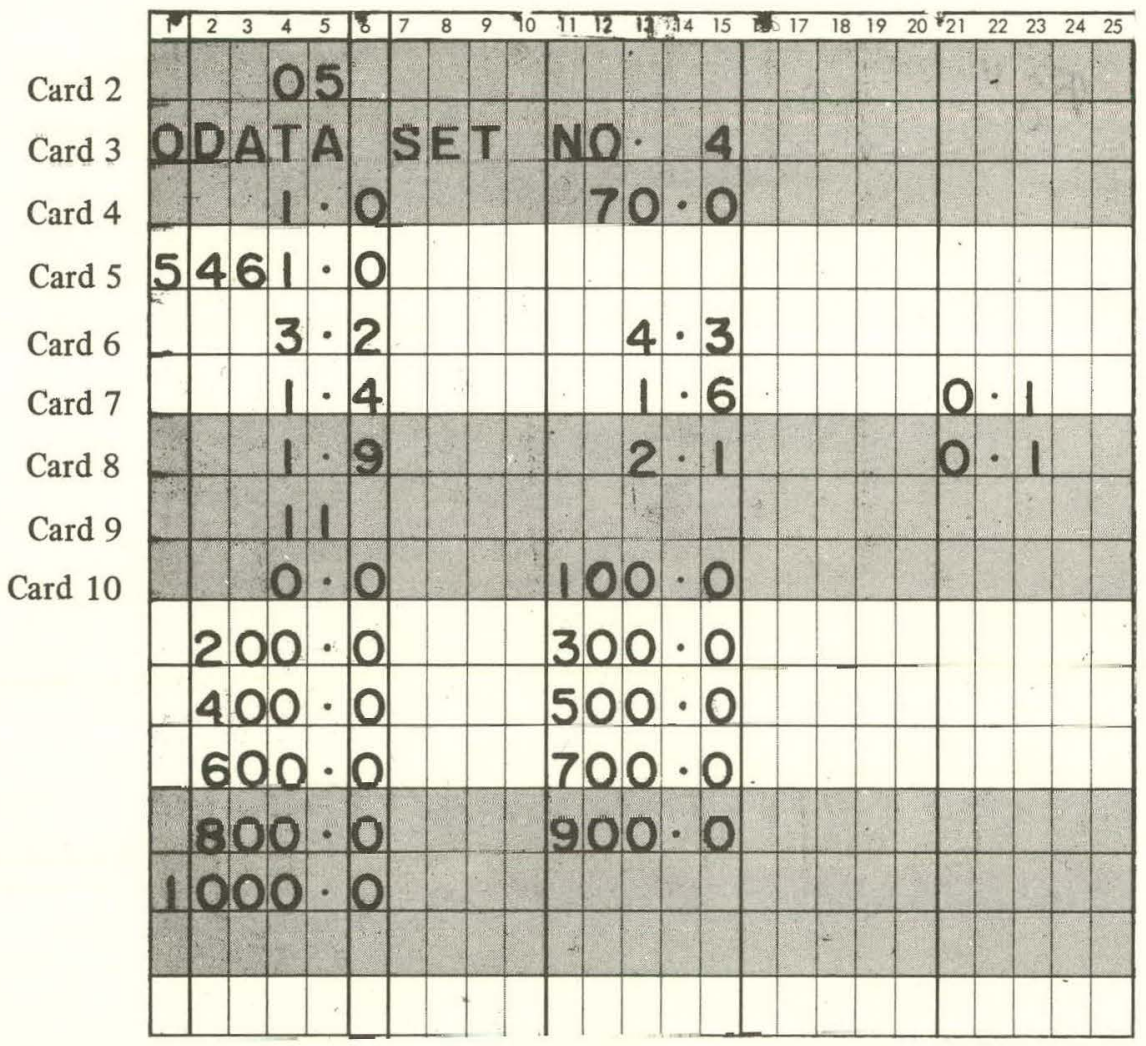

Card 2 - The value of IPICK.

Card 3 - The title card (column 1 reserved for the digit 0 for carriage control).

Card 4 - The index of refraction of the surrounding medium and the angle of incidence in two 10-column fields, respectively.

Card 5 - The wavelength of the light beam.

Card 6 - The real and imaginary parts of the refractive index of the substrate in two 10-column fields, respectively.

Card 7 - The minimum and maximum values of the $\mathrm{n}_{22}$ range and $\Delta \mathrm{n}_{22}$ in three 10-cólumn fields, respectively.

Card 8 - The minimum and maximum values of the $\mathrm{n}_{21}$ range and $\Delta \mathrm{n}_{21}$ in three 10-column fields, respectively.

Card 9 - The number of values of film thickness.

Cards 10-15 - The film thicknesses in two 10-column fields per card. 
FIGURE 12. Output Data Showing the Results of Part 4 of the Source Program.

THE OPTICAL PARAMETERS PSI AND DELTA DETERMINED BY THE METHOD OF ELLIPSOMETRY

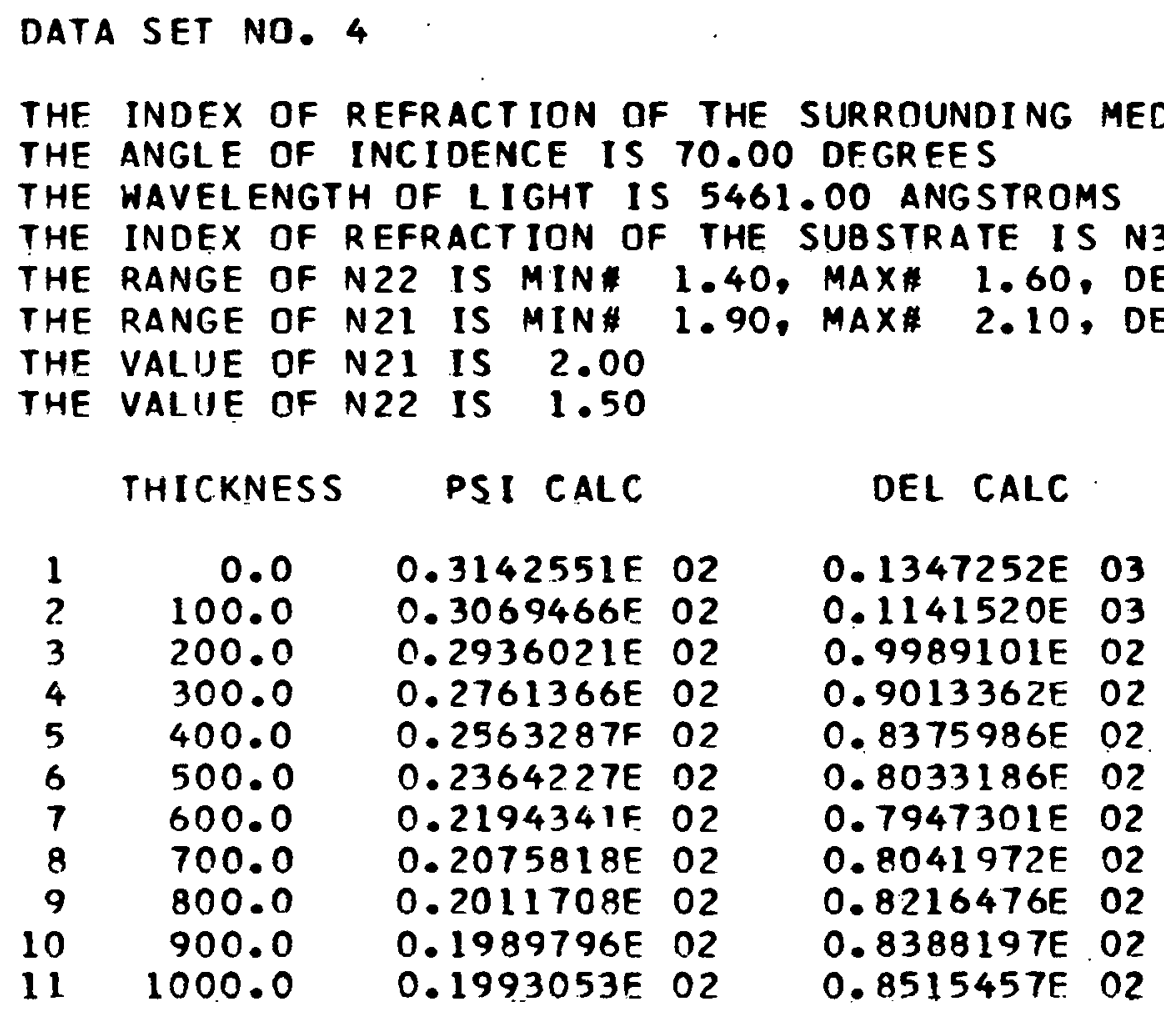


RFP-1 392

,

16 
APPENDIX A. Print-Out of the Source Program

Appendix A presents a complete print-out of the main program and the subroutine subprograms. 
A FORTRAN IV PROGRAM FOR COMPUTING THE THICKNESS OF A SURFACE FILM AND DETERMINING ITS INDEX OF REFRACTION BY THE METHOD OF ELLIPSOMETRY.

DIMENSION LABEL ( 18$)$, PSIP $(20)$, DELP $(20)$, EN2 $2(30), E N 21(2)$, , PS I $(30)$ DIMENS I ON DEL $(30), 02(30)$, OPN2 $1(30), N Q(30), D 2 I(2), E S U M(30)$ DIMENSION ERROR (30), AVN2 $1(30), \operatorname{SIGMA}(30), K 22(30), \mathrm{J} 21(30)$

\section{FORMAT ( I5)}

FORMAT ( $18 A 4)$

FORMAT ( $2 F 10.3)$

FORMAT (I 5/(2F10.4))

FORMAT('ITHE INDEX OF REFRACTION OF A CLEAN SURFACE DETERMINED', IIX, 'BY THE METHOD OF ELLIPSOMETRY')

FORMAT('OTHE INDEX OF REFRACTICN OF THE SURROUNDING MEDIUM IS',

$11 X, F 5.21$

FORMAT( THE ANGLE OF INCIDENCE IS',F6.?,1X, OAFFRFFS') FORMAT' ' $0 ', 4 X, ' P S I$ PRIME', $2 X$, 'DEL PRIME', $7 X, 1 N 31^{\prime}, 13 X,{ }^{\prime} N 32^{\prime} / 1$

FORMAT $(1 X, I 2,4 X, F 6.3,4 X, F 7.3,3 X, E 12.5,4 X, E 12.5)$

FORMAT (F10.4)

FORMAT ( $3 F 10.4)$

FORMATI'ITHE OPTICAL CONSTANT N2I FOR PSI AND DELTA OR NO',

IIX,' SOLUTION AT ALL''

format1' calculating the mean value of n2l for the value',

$11 X$, 'OF N22 USED'I

FORMATI" THE WAVELENGTH OF LIGHT IS',F8.2,1X, 'ANGSTROMS')

FORMATI' THE OPTICAL PARAMETERS OF THE SUBSTRATE ARE PSI',

$11 X$, 'PRIME $=1,1 X, F 7.3,1 X$, 'AND DEL PRIME $=1,1 X, F 8,31$

FORMATI" THE CALCULATED INDEX OF REFRACTION OF THE SUBSTRATE IS", $11 X, \cdot N 31=1, E 12.5,1 X, \cdot$ AND N32 = , E12.51

FORMATI" THE INDEX OF REFRACTION OF THE SUBSTRATE IS',

$11 X, 1 N 31=1,1 X, F 4,2,1 X, 1$ AND N32 $=1,1 X, F 4,2$ )

FORMATI' THE RANGE OF N22 IS MIN=1,F6.2,', ', 1X,'MAX =1,F6.2,', ',

$11 X$, 'DELTA $=1, F 6.21$

FORMATI' THE RANGE OF N21 IS MIN=1,FG.2,',

$11 X$, 'MAX $=$ 'FG.2)

FORMAT(' THE GIVEN TOLERANCE WHICH WAS TESTED IS', E12.5, $, 1,1 \mathrm{X}$,

1 'THE TEST VALUE IS', $1 X, 12)$

FORMAT' ' THE GIVEN TOLERANCE WHICH WAS EXECUTED IS', E12.5, $1,1,1 X$,

1 'THE TEST VALUE IS', $2 X, 121$

FORMATI' THE VALUE OF N22 IS',E12.51

FoRMAT 1 OCODE I MEANS THE abSOLUTE VALUE OF THE IMAGINARY', $1 X$,

1'THICKNESS IS LESS THAN OR EQUAL TO 0.1E-05 ANGSTROMS')

FORMATI" CODE 2 MEANS THE GIVEN TOLERANCE WAS ADEQUATE IN', $1 X$,

1'SELECTING N21')

FORMATI: CODE 3 MEANS THE GIVEN TOLERANCE WAS TOO SMALL IN',1X,

1 'SELECTING N21')

FORMATI: CODE 4 MEANS THE GIVEN TMLERANCE WAS TOO LARGE IN $1,1 X$,

1'SELECTING N2I')

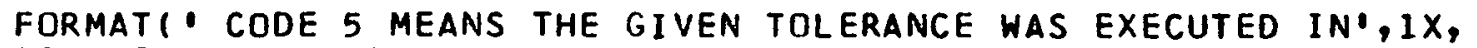

I'SELECTING N21')

FORMATI' CODE 6 MEANS NO SOLUTION DUE TO LIKE SIGNS OF THE', $1 X$,

I'IMAGINARY PARTS OF FILM THICKNESS')

FORMAT' CODE 7 MEANS NO SOLUTION, TOL TOO SMALL', test VALLIE', $1 X$, 1 'TOO SMALL, INCREASING ERROR IN COMPUTING N21\%

FORMATI' CODE 8 MEANS NO SOLUTION, TOL TOO SMALL, TEST VALUE', IX, 1'TOO SMALL, DECREASING ERROR IN COMPUTING N21') 
RFP-1392

1'TOO SMALL, INCREASING ERROR IN. COMPUTING N2I')

059 FORMATI" CODE 10 MEANS NO SOLUTION, TOL TOO LARGE, TEST VALUE', O6O $11 X$, TOO SMALL, DECREASING ERROR. IN COMPUTING N21'I

FORMAT $10^{\prime}$, $12 X, ' C O D E \cdot / 1$

34 FORMAT $(1 X, 12,3 X, F 6,3,3 X, F 7,3,41 X, I 1)$

FORMAT $(1 X, 12,3 X, F 6,3,3 X, F 7,3,3 X, E 14,7,5 X, E 12,5,7 X, 11)$

064

FORMAT' 'OTHE MEAN VALUE OF N2I IS',E14.7,', THE STANDARD ERROR',

065

$11 X, ' F O R ', 1 X, I 2, '$ VALUES OF N21 IS',E14.7)

FORMATI!ITHE THICKNESS OF A SU

$11 X$, 'METHOD OF ELLIPSOMETRY')

38 FORMAT( THE VALUE OF N2I IS , $1 X, F 5.2)$

39 FORMAT(' THE VALUE OF N22 IS', $1 X, F 5,2)$

40

FORMAT: THE CALCULATED VALUE OF N2I IS, E $14.7,1 \mathrm{X}$,

1'WITH A STANDARD ERROR OF',E12.5)

41 FORMAT! THE SELECTED VALUE OF N22 IS!, $11 X, E 12.5)$

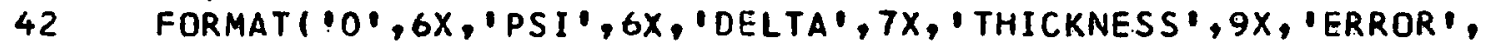
$13 X$, QUADRANT'/1

43 FORMAT $(1 X, 12,3 X, F 6,3,3 X, F 7,3,3 X, E 14,7,3 X, E 12,5,3 X, 11)$

066

067

068

069

070

071

072

073

074

075

0.76

077

078

44 FORMATI'ITHE OPTICAL PARAMETERS PSI AND DELTA DETERMINED BY THE'. $11 X$, 'METHOD OF ELLIPSOMETRY')

45 FORMAT!' THE RANGE OF N21 IS MIN=',F6.2,',',1X,'MAX=',F6.2,',', $11 X$, DELTA $=0, F 6.2)$

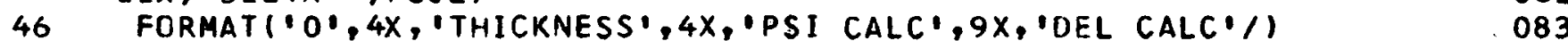

47 FORMAT $(1 X, I 2,3 X, F 6,1,3 X, E 14,7,3 X, E 14.7)$

$J J=1$

$K K=3$

080

081

082

084

085

086

C

COMPUTING THE INDEX OF REFRACTION OF A CLEAN SURFACE.

087

WRITING THE RESULTS.

088

089

090

READING AND DERIVING INPUT DATA.

091

READ(JJ, 1 INUMBER

092

093

DO 200 KRET $=1$, NUMBER

094

READ(JJ,I)IPICK

095

GO TO $(1005,1010,1015,1015,1020), I P I C K \quad 096$

1005 READ $(J \mathrm{~J}, 2) L A B E L$

097 .

READ(J」,3) ENI, PHII

READ $(J \mathrm{~J}, 4)$ NSET $S,(P S I P(J), D E L P(J), J=1, N S E T S)$

098

WR I TE $(K K, 5)$

WR ITE $(K K, 2) L A B E L$

099

100

WR I TE $(K K, 6)$ EN 1

101

WR ITE (KK, 7$)$ PHI 1

102

103

WR I TE $(K K, 8)$

104

EN $31=0.0$

105

EN $32=0.0$

106

DO $205 \mathrm{~J}=1$, NSETS

107

108

CALL EN3(EN1,PHI1,PSIP(J), DELP(J),EN31,EN32)

109

WR ITE $(K K, 9) J, P S I P(J), D E L P(J), E N 31, E N 32$

205 C.DNTINISE

GO TO 200

110

111

1010 READ(JJ,2) LABEL

112

READ (JJ, 3 ) EN1, PHI 1

113

READ(JJ, 10$)$ WAVE

RFAD(.1.1, 3)FN31, EN32

114

READ (JJ,3) EN21(1), EN22(1) 
RFP-1392

READ (JJ, 4)NSETS, (PSI (J),DEL $(J), J=1, N S E T S) \quad 117$

GO TO 1025

118

1015 READ (JJ,2)LABEL

119

READ (JJ,3)EN 1 , PHI 1

120

READ (JJ, 10 ) WAVE

IFI I P ICK-4) 50,51,51

121

122

51 READ (JJ, 3)EN31, EN32

123

GO TO 1030

124

50 READ (JJ,3)PSIP(1), DELP(1)

125

EN $31=0.0$

126

$E N 32=0.0$

127

CALL EN3(EN1, PHI 1,PSIP(1),DELP(1),EN31,EN32) 128

1030 READ (JJ, 11) EN22N,EN22X,ON22.

129

READ (JJ, 3) EN21N, EN21X

130

READ $(J J, 4) N S E T S,(P S I(J), D E L(J), J=1, N S E T S)$

131

READ (JJ,IO)TOL

READ(JJ, I)ITOL

132

133

READ (JJ, 1$)$ NTEST

134

DO $210 \mathrm{~K}=1,30$

135

$E N 22(K)=0.0$

136

210 CONT INUE

N22 $=0$

CALL RANGE (EN22N,EN22X, DN22, N22, EN22)

137

138

139

GO TO 1035

1020 READ (JJ,2)LABEL

READ (JJ,3) EN 1, PHI 1

READ (JJ, 10) HAVE

READ $(J J, 3)$ EN $31, E N 32$

READ (JJ, 11 ) EN22N, EN22X,DN22

140

141

142

143.

144

145

146

READ (JJ, 11 ) EN2 1N, EN21X, DN2 1

READ $(J J, 4)$ NSETS, $(D 2(J), J=1$, NSETS )

DO $215 K=1,30$

EN22 $(K)=0.0$

OPN21 $(K)=0.0$

147

148

149

150

151

CONT INUE

$N 2 Z=0$

CALL RANGE (EN22N, EN22X, DN22, N22, EN22)

152

$N 21=0$

CALL RANGE (EN21N, EN21X, DN21, N21, OPN21)

153

154

155

GO TO 1040

156

$\begin{array}{lll}C & & \\ C & & 157 \\ C & & 158\end{array}$

C $\quad 159$

1035 DO $220 \quad K=1, N 22$

DO $225 \mathrm{~J}=1$, NSETS

$D 2(J)=0.0$

NQ $(J)=0$

160

161

162

163

164

165

166

167

1. $S=0$

168

$\mathrm{RADD}=0.0$

169

$L D=0$

170

$S=0.0$

171

$J C 2 S=0$

$K C S=0$

172

173

$\mathrm{LCS}=0$

174 


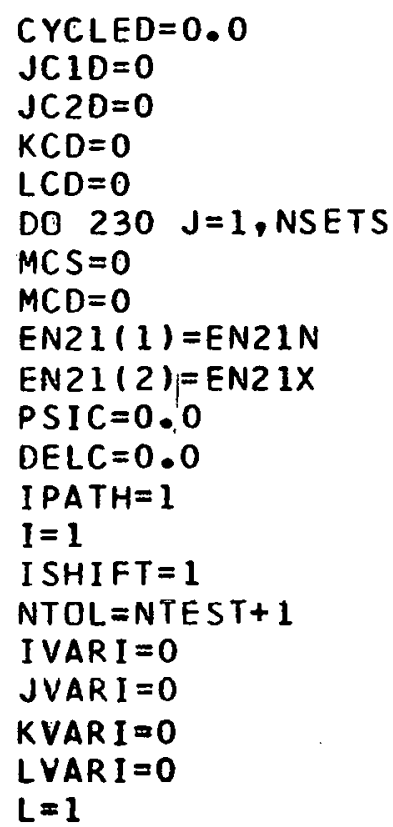

CALL RID2 (EN22(K), PSI ( J),DEL(J),EN21(I), ISHIFT, D2 (J), NQ (J),D2I (I), 197 1PSIC, DELC, EN31, EN32, EN 1, PHII, WAVE, RADS, LS, RADD, LD, CYCLES, I, JC IS, $2 J C 2 S, K C S, L C S, M C S, C Y C L E D, J C 10, J C 2 D, K C D, L C D, M C D, J, I P$ ICK ).

RADS $=$ CYCLES

RADD $=$ CYCLED

$$
\text { IPATH }=3
$$

GO TO 1050

$6102 I(1)-02 I(2)$

$63 \quad E P S I=P S I(J)-P S I C$ 
$\operatorname{ERROR}(J)=\operatorname{ESUM}(L) \quad 233$

IDIAG $=5 \quad 234$

GO TO $1045 \quad 235$

$66 \quad$ KVARI-KVARI+1 236

$\begin{array}{ll}\text { NTOL }=L & 237\end{array}$

$\begin{array}{llr}65 & \text { IF }(L-2) 68,69,69 & 238\end{array}$

$68 \quad L=L+1 \quad 239$

$\begin{array}{ll}\text { GO TO } 1055 & 240\end{array}$

69 IF (KVARI -L) 70,71,71 241

$\begin{array}{ll}71 \text { LVARI }=1 & 242\end{array}$

GO TO 1060

70 IF(NTOL-L)72,73,1.060 . 244

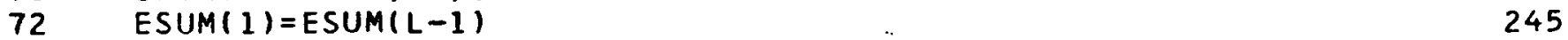

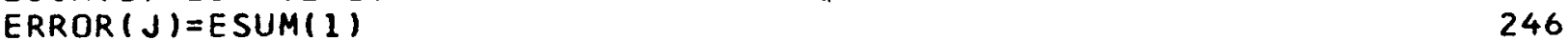

IDIAG $=2 \quad 247$

GO TO $1065 \quad 248$

$73 \operatorname{ESUM}(1)=\operatorname{ESUM}(L) \quad 249$

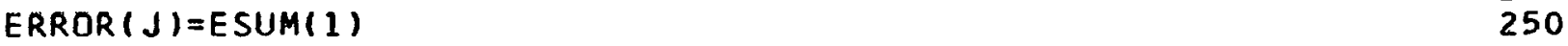

IDIAG $=2 \quad 251$

GO TO $1065 \quad 252$

1060 IFIESUM(L)-ESUM(L-1))74,74,75 253

75 JVARI $=1 \quad 254$

IF(IVARI) 76,76,77

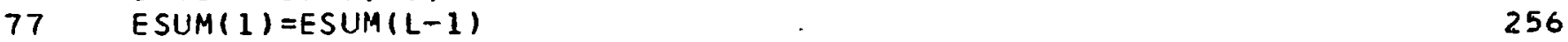

$1070 \operatorname{ERROR}(J)=E S U M(1) \quad 257$

IF(LVARI) $78,78,79 \quad$. 258

$\begin{array}{ll}78 & 25 I A G=3\end{array}$

GO TO $1065 \quad 260$

79 IDIAG $=4 \quad 261$

GO TO $1065 \quad 262$

74 IVARI $=1 \quad 263$

IF( JVARI) 76,76,80

$80 \quad \operatorname{ESUM}(1)=E S U M(L) \quad 265$

GO TO $1070 \quad 266$

\begin{tabular}{ll}
76 & IF $(L-N T E S T) 81,82,82$ \\
\hline
\end{tabular}

$81 \mathrm{~L}=L+1 \quad 268$

GO TO $1055 \quad 269$

82 IF(KVARI-L) 83,84,84 270

84 IF(IVARI) $85,85,86 \quad 271$

86. IDIAG $=10 \quad 272$

60 TO $1045 \quad 279$

85 IDIAG-9 274

$\begin{array}{lr}\text { GO TO } 1045 & 275\end{array}$

83 IF(IVARI) 87,87,88 276

88 IDIAG $=8 \quad 277$

$\begin{array}{ll}\text { GO TO } 1045 & 278\end{array}$

87 IDIAG $=7 \quad 279$

GO TO $1045 \quad$. 280

1065 AVEP $=(E N 21(1)+E N 21(2)) / 2.0 \quad 281$

$\begin{array}{ll}A V E 2=E N 21(2) & 282\end{array}$

EN2 $1(2)=$ AVEP $\quad 283$

$A V E L=(E N 21(1)+A V E P) / 2.0 \quad \cdot \quad 284$

$A V E R=(A V E P+A V E 2) / 2.0 \quad 285$

DO $235 \mathrm{~L}=2,3 \quad 286$

$D 2 I(2)=0.0 \quad 287$

CALL RID2 (EN22(K), PSI ( J), DEL (J), EN2 I (2), ISHIFT,D2 $(J), N Q(J), D 2 I(2), 288$

IPSIC, DELC, EN31, EN32, EN1, PHI1, WAVE, RADS, LS, RADD, LD,CYCLES, I, JCIS, 289

$2 J C 2 S, K C S, L C S, M C S, C Y C L E D, J C 1 D, J C 2 D, K C D, L C D, M C D, J, I P I C K) \quad 290$ 


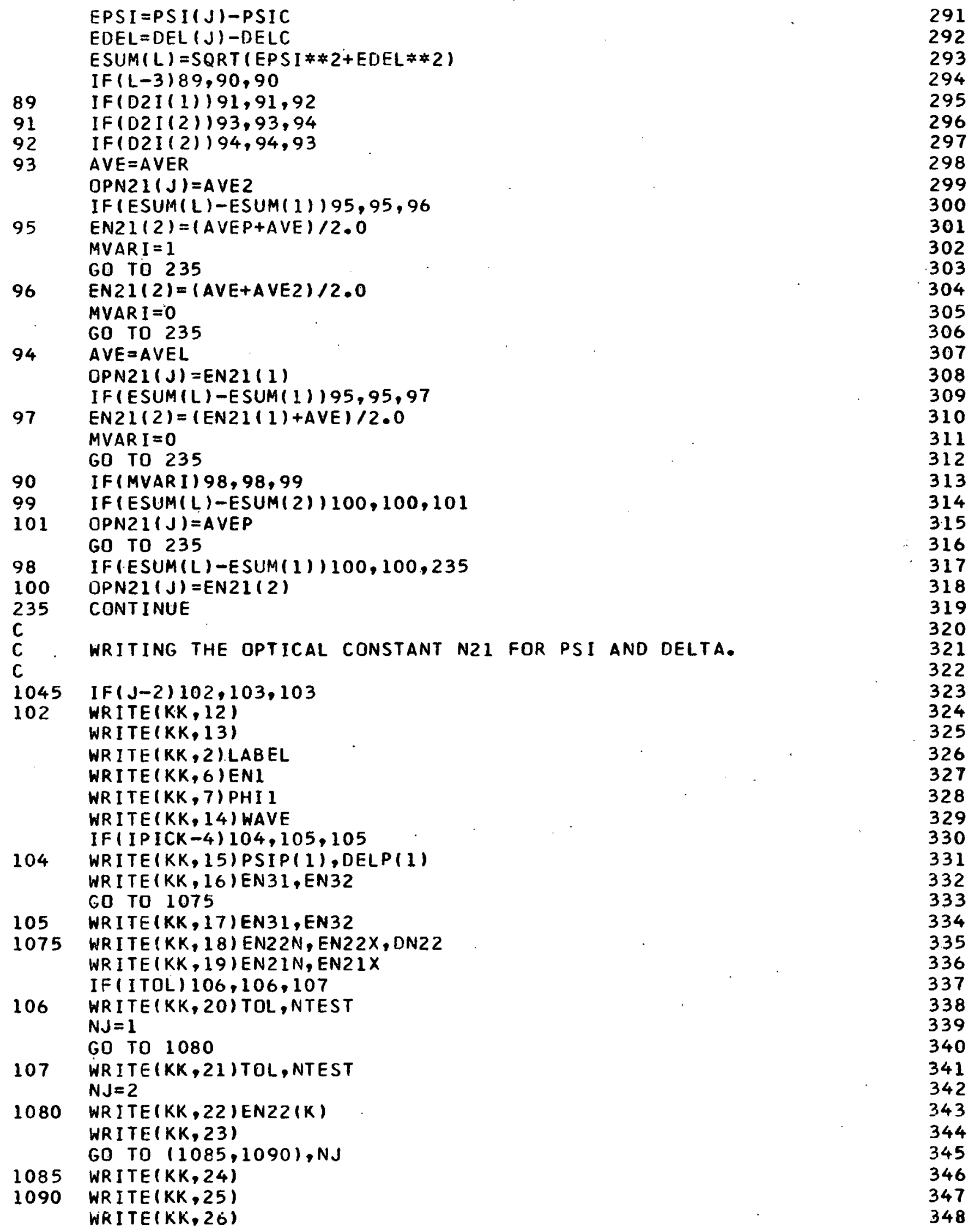


RFP-1392

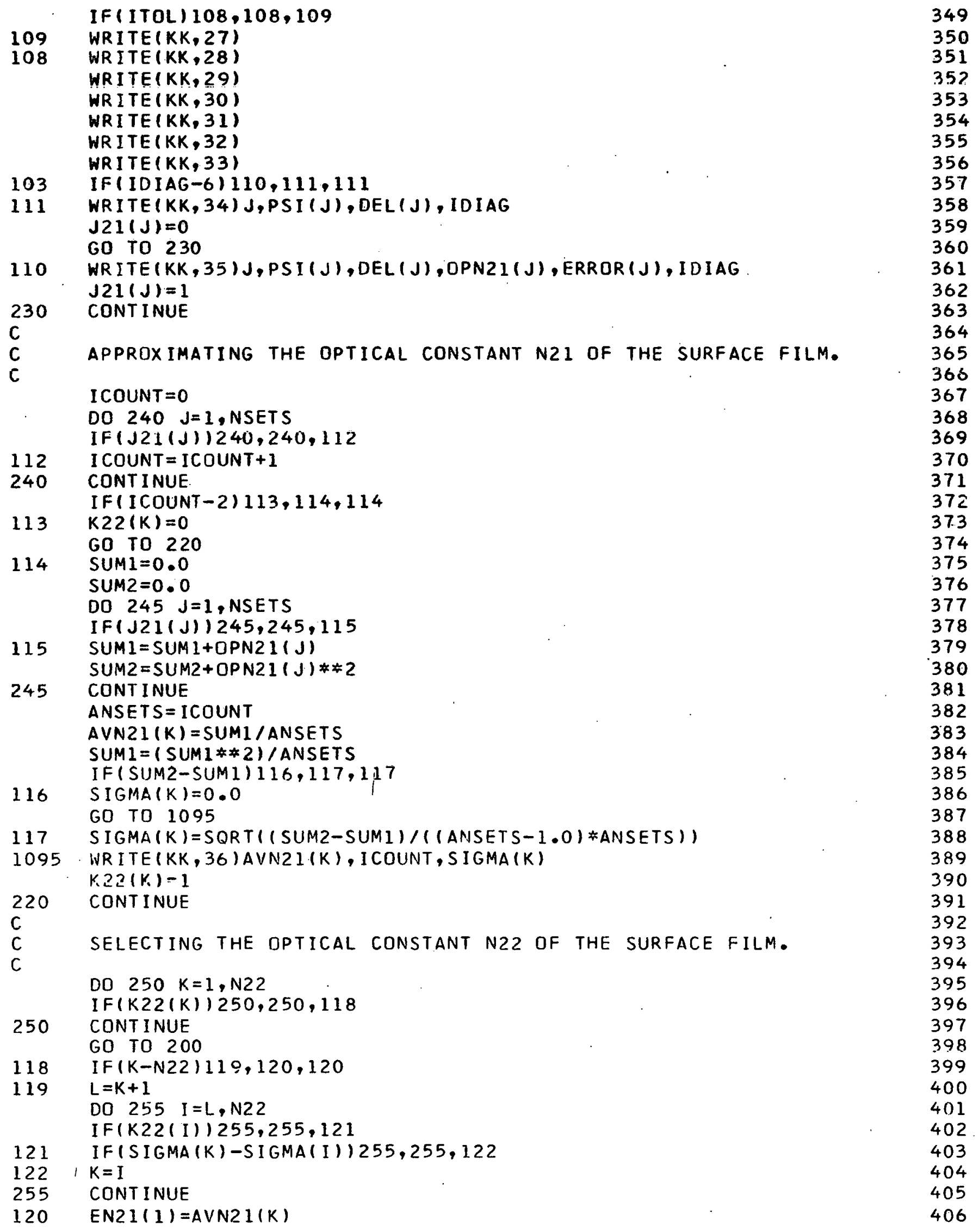




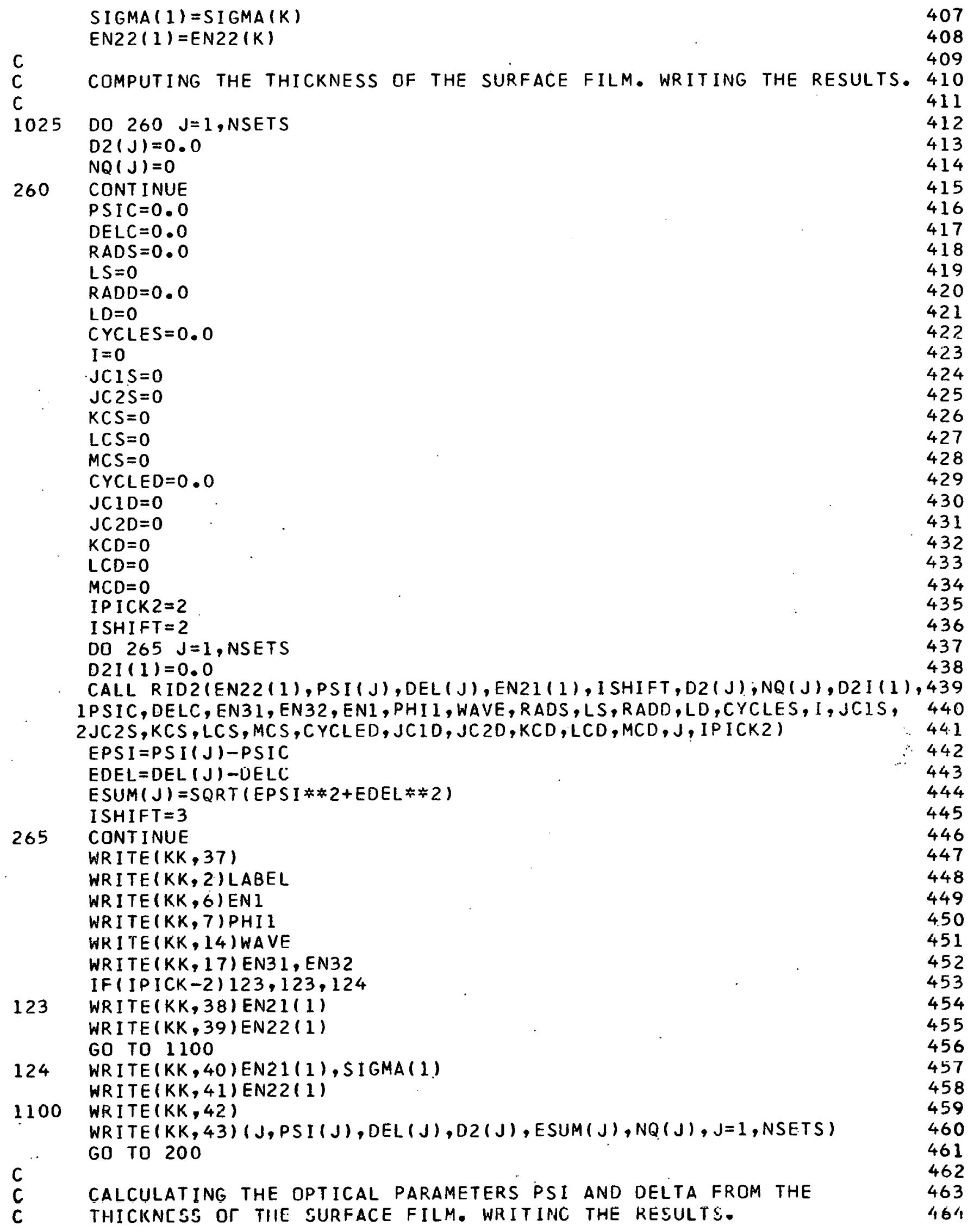


RFP-1392

C

1040 DO $270 \mathrm{~J}=1$,NSETS

465

$\operatorname{PSI}(J)=0.0$

$\operatorname{DEL}(J)=0.0$

466

467

$N Q(J)=0$

270 CONTINUE

468

469

D2 I (I) $=0.0$

470

P S I C $=0.0$

471

DELC $=0.0$

$-472$

RADS $=0.0$

473

$L S=0$

$R A D D=0.0$

474

475

$\angle D=0$ :

476

$C Y C L E S=0.0$

477

IC $=0$

478

479

$J C 1 S=0$

$J C 2 S=0$

$K C S=0$

LCS $=0$.

$M C S=0$

480

481

487

483

CYCLED $=0.0$

484

$J C 1 D=0$

$J C 2 D=0$

485

486

$K C D=0$

$L C D=0$

$M C D=0$

DO $275 K=1, N 22$

DO $280 \quad I=1, N 21$

487

488

489

490

WR I TE $(K K, 44)$

491

492

WR I TE $(K K, 2) L A B E L$

493

494

- WR ITE $(K K, 6)$ EN I

495

WRITE (KK, 7$)$ PHI I

496

WR I TE (KK, 14$)$ WA VE

497

498

WRITE $(K K, 17)$ EN31, EN32

WRITE $(K K, 18) E N 22 N, E N 22 X, D N 22$

499

WRITE (KK, 45) EN2 IN, EN21X, DN2 1

500

WR ITE (KK, 38$)$ OPN2I (I)

501

WRITE $(K K, 39)$ EN22(K)

WRITE $(K K, 46)$.

I SHIFT $=4$

504

DO $285 \mathrm{~J}=1$, NSETS

505

CALL RID2 (EN22(K), PSI ( J), DEL ( J), OPN21(I), ISHIFT,D2(J), NQ (J), 506 $1 D 2 I(1), P S I C, D E L C, E N 31$, EN32, EN 1, PHI1, WAVE, RADS, LS, RADD, LD, CYCLES, 507

$2 I C, J C I S, J C 2 S, K C S, L C S, M C S, C Y C L E D, J C 1 D, J C 2 D, K C D, L C D, M C D, J, I P I C K) \quad 508$ WR ITE $(K K, 47) \mathrm{J}, \mathrm{D} 2(\mathrm{~J}), \mathrm{PSIC}, \mathrm{DELC}$

I SHIFT $=5$

509

510

CONT INUE

511

CONTINUE

512

CONT INUE

513

514

CONTINUE

515

STOP

516

END

517

SUBROUTINE EN3 (EN1, PHI1, PSIP, DELP, EN31, EN32)

518

$S P H I=S I N(P H I 1 / 57.29578)$

CPHI $=$ COS $(P H I 1 / 57.29578)$

519

SPS I $=$ SIN( $2.0 * P S I P / 57.29578)$

520

CPSI $=\operatorname{COS}(2.0 * P S I P / 57.29578) * 2$

521

SOEL $=$ SIN(DELP/57.29578)

.522 
CDEL $=\operatorname{COS}(D E L P / 57.29578) \quad 523$

$\mathrm{T}=\mathrm{SPHI} / \mathrm{CPHI} \quad 524$

$A V=T * T * C P S I /(1,1.0+S P S I * C D E L) * 2)$

$A 1=E N I * 2 * S P H I * 2 *(1.0+A V) \quad 526$

$A 2=E N 1 * T * S P H I * S P S I * S D E L /(1.0+S P S I * C D E L)$

$A=A 1-A 2 \# 2 \quad 528$

$A 3=(A 1-E N I * 2 * S P H I * 2) / A I$

$B=2.0 * A 2 * S Q R T(A 1 * A 3) \quad 530$

$S=S Q R T(A * A+B * B) \quad 531$

EN31 $=\operatorname{SQRT}((S+A) / 2.0) \quad 532$

EN32=SQRT $((S-A) / 2.0) \quad 533$

RETURN

END $\quad$. 535

SUBROUTINE RANGE(ENI, ENF, DELTA, N, EN)

DIMENSION EN(30)

$P=(E N F-E N I) / D E L T A+1.1 \quad 538$

EN $(1)=E N I \quad 539$

$N=P \quad 540$

IF $(\mathrm{N}-1) 2,2,4$

DO $100 \quad I=2, N \quad 542$

$E N(I)=E N(I-I)+D E L T A \quad 543$

100 CONTINUE $\quad$.

2 RETURN $r$\begin{tabular}{lr}
1005 \\
\hline
\end{tabular}

END $\quad 546$

SUBROUTINE RID2 IEN22, PSI, DEL, EN21, ISHIFT, D2, NQ, D2I, PSIC, DELC, . 547

$1 E N 31$, EN32, EN1, PHI1, WAVE, RADS, LS, RADD, LD, CYCLES, IC, JC 1S, JC2S, $\quad 548$

2KCS,LCS, MCS, CYCLED, JC ID, JC2D,KCD, LCD, MCD, J, IPICK)

C

\section{CALCULATING FILM THICKNESS D2.}

550

551

552

GO TO $(2,2,4,2,8)$, ISHIFT

$2 . A P H=C O S(P H I 1 / 57.29578) \quad 554$

APHS = APH*APH $\quad 555$

$A 1=E N 1 * E N 1 \quad: 556$

$A 31=E N 31 * E N 31 \quad \because 557$

$A 32=E N 32 * E N 32 \quad: 558$

$A 11=A 31+A 32 \quad \checkmark 559$

$A G 3=1.0-(A 1 * A 31-A 1 * A 32+A P H S *(A 1 * A 32-A 1 * A 31)) /(A 11 * A 11) . \quad 560$

$A H 3=(2.0 * A 1 * E N 31 * E N 32 *(1.0-A P H S)) /(A 11 * A 11)$

$A R H O 3=0.0 \quad 562$

CALL QTEST(AH3,AG3,ARHO3) 563

ARHO $3=A R H O 3 \approx 0.5 \quad 564$

$A 2=(A G 3 * A G 3+A H 3 * A H 3) * 0.25 \quad 565$

$A I 3=A 2 * \operatorname{COS}(A R H 03) . \quad 566$

AJ 3 $=A 2 *$ S IN (ARHO3) $\quad 567$

-A21=EN21*EN21 $\quad \vdots \quad 568$

$A 22=E N 22 * E N 22 \quad 569$

$A 12=A 21+A 22 \quad 570$

$A G 2=1.0-(A 1 * A 21-A 1 * A 22+A P H S *(A 1 * A 22-A 1 * A 21)) /(A 12 * A 12)$

$A H 2=(2,0 * A 1 * E N 2) * E N 22 *(1,0-A P H S)) /(A 12 * A 12)$

$A R H O 2=0.0 \quad 573$

CALL QTEST (AH2, AG2, ARHO2) $\quad 574$

ARHO2=ARHO2 $\$ 0.5 \quad 575$

$A 2=(A G 2 * A G 2+A H 2 * A H 2) * 0.25$

AI $2=A 2 * \operatorname{COS}(A R H O 2) \quad 577$

$A J 2=A 2 * \operatorname{SIN}(A R H O 2) \quad 578$

$A U=E N 21 * A J 2+E N 22 * A 12 \quad 579$

$A V=E N 21 * A 12-E N 22 * A J 2 \quad 580$ 
$A I=A U * A U+A V * A V$

$A 2=-W A V E /(4.0 * 3.141593)$

581

$A P 2=A \cup / A 2$

582

$B P 2=A V / A 2$

C

$B 1 N 12=E N 1 * A P H-E N 21 * A I 2+E N 22 * A J 2$

583

584

585

$B 2 N 12=E N 1 * A P H+E N 21 * A 12-E N 22 * A J 2$

586

$B 3 N 12=E N 21 * A J 2+E N 22 * A I 2$

587

$B 1 P 12=E N 21 * A P H-E N 1 * A I 2$

588

$B 2 P 12=E N 22 * A P H-E N 1 * A J 2$

589

$B 3 P 12=E N 21 * A P H+E N 1 * A I 2$

$B 4 P 12=E N 22 * A P H+E N 1 * A J 2$

590

591

$B 1 N 23=E N 21 * A I 2-E N 22 * A J 2-E N 31 * A I 3+E N 32 * A J 3$

592

$B 2 N 23=E N 21 * A I 2-E N 22 * A J 2+E N 31 * A I 3-E N 32 * A J 3$

593

$B 3 N 23=E N 31 * A J 3+E N 32 * A I 3-E N 21 * A J 2-E N 22 * A 12$

$B 4 N 23=E N 31 * A J 3+E N 32 * A I 3+E N 21 * A J 2+E N 22 * A I 2$

594

595

$B 1 P 23=E N 31 * A I 2-E N 32 * A J 2-E N 21 * A I 3+E N 22 * A J 3$

596

$B 2 P 23=E N 31 * A 12-E N 32 * A J 2+E N 21 * A 13-E N 22 * A J 3$

597

$B 3 P 23=E N 21 * A J 3+E N 22 * A 13-E N 31 * A J 2-E N 32 * A 12$

598

$B 4 P 23=E N 21 * A J 3+E N 22 * A I 3+E N 31 * A J 2+E N 32 * A 12$

C

$C 1=(B 1 N 12 * B 2 N 12-B 3 N 12 * B 3 N 12) /(B 2 N 12 * B 2 N 12+B 3 N 12 * B 3 N 12)$

599

600

601

$C 2=(B 1 N 12 * B 3 N 12+B 3 N 12 * B 2 N 12) /(B 2 N 12 * B 2 N 12+B 3 N 12 * B 3 N 12)$

602

$C 3=(B 1 P 12 * B 3 P 12+B 2 P 12 * B 4 P 12) /(B 3 P 12 * B 3 P 12+B 4 P 12 * B 4 P 12)$

603

$C 4=(B 1 P 12 * B 4 P 12-B 2 P 12 * B 3 P 12) /(B 3 P 12 * B 3 P 12+B 4 P 12 * B 4 P 12)$

604

$C 5=(B 1 N 23 * B 2 N 23-B 3 N 23 * B 4 N 23) /(B 2 N 23 * B 2 N 23+B 4 N 23 * B 4 N 23)$

605

$C 6=(B 1 N 23 * B 4 N 23+B 3 N 23 * B 2 N 23) /(B 2 N 23 * B 2 N 23+B 4 N 23 * B 4 N 23)$

606

607

$C 7=(B 1 P 23 * B 2 P 23-B 3 P 23 * B 4 P 23) /(B 2 P 23 * 82 P 23+B 4 P 23 * B 4 P 23)$

608

$C 8=(B 1 P 23 * B 4 P 23+B 3 P 23 * B 2 P 23) /(B 2 P 23 * B 2 P 23+B 4 P 23 * B 4 P 23)$

609

GO TO $(4,4,8,8)$, ISHIFT

C

CPSI $=$ COS (PSI $1 / 57.29578)$

610

611

612

SPSI = SIN(PSI/57.29578)

613

$T P=S P S I / C P S I$

$S D=S I N(D E L / 57.29578)$

$C D=\operatorname{COS}(D E L / 57.29578)$

$A Q 1=C 3 * C 5 * C 7 * C D * T P-C 4 * C 5 * C 7 * S D * T P-C 3 * C 5 * C 8 * S D * T P-C 4 * C 5 * C 8 * C D * T P$ $1-C 3 * C 6 * C 7 * S D * T P-C 4 * C 6 * C 7 * C D * T P-C 3 * C 6 * C 8 * C D * T P+C 4 * C 6 * C 8 * S D * T P$

$2-C_{1} * C 5 * C 7+C 1 * C 6 * C 8+C 2 * C 6 * C 7+C 2 * C 5 * C 8$

$A Q 2=C 3 * C 5 * C 7 * S D * T P+C 4 * C 5 * C 7 * C D * T P+C 3 * C 5 * C 8 * C D * T P+C 3 * C 6 * C 7 * C D * T P$

$1-C 4 * C 5 * C 8 * S D * T P-C 4 * C 6 * C 7 * S D * T P-C 3 * C 6 * C 8 * S D * T P-C 4 * C 6 * C 8 * C D * T P$

$2+C 2 * C 6 * C 8-C 2 * C 5 * C 7-C 1 * C 5 * C 8-C 1 * C 6 * C 7$

$B Q 1=C 5 * C D * T P-C 6 * S D * T P+C 1 * C 3 * C 7 * C D * T P-C 1 * C 4 * C 8 * C D * T P$

$1-C 2 * C 3 * C 8 * C D * T P-C 2 * C 4 * C 7 * C D * T P-C 1 * C 3 * C 8 * S D * T P-C 1 * C 4 * C 7 * S D * T P$

$2-C 2 * C 3 * C 7 * S D * T P+C 2 * C 4 * C 8 * S D * T P-C 1 * C 3 * C 5+C 2 * C 4 * C 5+C 2 * C 3 * C 6$

$3+\mathrm{C} 1 * \mathrm{C} 4 * \mathrm{C} 6-\mathrm{C} 7$

$B Q 2=C 6 * C D * T P+C 5 * S D * T P+C 1 * C 3 * C 8 * C D * T P+C 1 * C 4 * C 7 * C D * T P$

$1+C 2 * C 3 * C 7 * C D * T P-C 2 * C 4 * C 8 * C D * T P+C 1 * C 3 * C 7 * S D * T P-C 1 * C 4 * C 8 * S D * T P$

$2-\mathrm{C} 2 * \mathrm{C} 3 * \mathrm{C} 8 * \mathrm{SD} * \mathrm{TP}-\mathrm{C} 2 * \mathrm{C} 4 * \mathrm{C} 7 * \mathrm{SD} * \mathrm{TP}-\mathrm{C} 2 * \mathrm{C} 3 * \mathrm{C} 5-\mathrm{C} 1 * \mathrm{C} 4 * \mathrm{C} 5-\mathrm{C} 1 * \mathrm{C} 3 * \mathrm{C} 6$

$3+\mathrm{C} 2 * \mathrm{C}_{4} * \mathrm{C} 6-\mathrm{C} 8$

$\mathrm{CQ} 1=\mathrm{C} 1 * \mathrm{CD} * \mathrm{TP}-\mathrm{C} 2 * \mathrm{SD} * \mathrm{TP}-\mathrm{C} 3$

614

615

616

617

618

619

620

621

622

623

624

625

626

627

628

629

630

631

$C Q 2=C 2 * C D * T P+C 1 * S B * T P-C 4$

632

633

$E A=B Q 1 * B Q 1-B Q 2 * B Q 2-4 \cdot 0 * A Q 1 * C Q 1+4 \cdot 0 * A Q 2 * C Q 2$

634

$E B=2.0 * B Q 1 * B Q 2-4.0 * A Q 1 * C Q 2-4.0 * A Q 2 * C Q 1$

$E R H O I=0.0$

CALL QTEST (EB, EA, ERHO1)

635

636

637

$E R H O I=E R H O I * 0.5$

638 
$E 1=(E A * E A+E B * E B) * 0.25$

$E 2=2.0 *(A Q 1 * A Q 1+A Q 2 * A Q 2)$

640

$E R H O 2=E 1 *(A Q 1 * C O S(E R H O 1)+A Q 2 * S I N(E R H O 1))$

641

$X S U M=(-A Q 1 * B Q 1-A Q 2 * B Q 2+E R H O 2) / E 2$

$X D I F F=(-A Q 1 * B Q 1-A Q 2 * B Q 2-E R H O 2) / E 2$

642

643

$E R H O 3=E 1 *(A Q 1 * S I N(E R H O 1)-A Q 2 * C O S(E R H O 1))$

644

YSUM $=(A Q 2 * B Q 1-A Q 1 * B Q 2+E R H 03) / E 2$

YDIFF $=(A Q 2 * B Q 1-A Q 1 * B Q 2-E R H O 3) / E 2$

645

$Z S U M=A L O G(S Q R T(X S U M * X S U M+Y S U M * Y S U M))$

646

$2 D I F F=A L O G(S Q R T(X D I F F * X D I F F+Y D I F F * Y D I F F))$

647

IF( IPICK-2) $18,18,16$

$18 \quad$ RHOS $=0.0$

648

649

$N Q S=0$

650

651

CALL QTEST2 (YSUM, X SUM, RHOS, NQS, RADS, LS, MCS)

652

RHOD $=0.0$

653

$N Q D=0$

654

CALL QTEST2(YDIFF, XDIFF, RHOD, NQD, RADD, LD, MCD)

655

GO TO 20

$16 \quad$ RHOS $=0.0$

656

657

NQS $=0$

658

CALL QTEST3(YSUM, XSUM, RHOS, NQS, RADS, LS, CYCLES, IC, JCIS, JC2S,

659

IKCS,J, LCS,MCS)

$\mathrm{RHOD}=0.0$

NQD $=0$

CALL QTEST3IYDIFF, XDIFF, RHOD, NQD, RADD, LD, CYCLED, IC, JC 1D, JC2D,

$1 K C D, J, L C D, M C D)$

$20 \quad S S U M=(A U * Z S U M+A V * R H O S) / A I$

SDIFF $=(A U * Z D I F F+A V * R H O D) / A 1$

$T S U M=(A U * R H O S-A V * Z S U M) / A 1$

660

661

662

$\because 663$

664

665

.666

667

TDIFF $=(A U * R H O D-A V \div Z O I F F) / A 1$

668

$D 2 S=A 2 * S S U M$

$D 2 D=A 2 * S D I F F$

I D2SI $=A 2 * T$ SUM

669

670

671

$D 2 D I=A 2 * 1 U 1 F F$

672

673

I F ( ABS (D2SI)-ABS(D2DI ) ) 10,10,12

674

$D 2=D 2 S$

$N Q=N Q S$

$D 2 I=D 2 S I$

GO TO 14

675

676

677

$D 2=D 2 D$

$N Q=N Q D$

678

679

$\mathrm{D} 2 \mathrm{I}=\mathrm{D} 2 \mathrm{DI}$

680

GO TO $(6,8,8)$, I SHIFT

681

682

CALCULATING PSI AND DELTA.

683

684

$C P 2=\operatorname{EXP}(A P 2 * D 2) * \operatorname{COS}(B P 2 * D 2)$

685

$D P 2=\operatorname{EXP}(A P 2 * D 2) * \operatorname{SIN}(B P 2 * D 2)$

686

$E P 2=C 3+C 7 * C P 2-C 8 * D P 2$

$F P 2=C 4+C 7 * D P 2+C 8 * C P 2$

687

688

$G P 2=1.0+C 3 * C 7 * C P 2-C 3 * C 8 * D P 2-C 4 * C 7 * D P 2-C 4 * C 8 * C P 2$

689

$\mathrm{HP} 2=\mathrm{C} 3 * \mathrm{C} 7 * \mathrm{DP} 2+\mathrm{C} 3 * \mathrm{C} 8 * \mathrm{CP} 2+\mathrm{C} 4 * \mathrm{C} 7 * \mathrm{CP} 2-\mathrm{C} 4 * \mathrm{C} 8 * \mathrm{DP} 2$

690

$A K P 2=(E P 2 * G P 2+F P 2 * H P 2) /(G P 2 * G P 2+H P 2 * H P 2)$

691

$A L P 2=(F P 2 * G P 2-E P 2 * H P 2) /(G P 2 * G P 2+H P 2 * H P 2)$

692

$E N 2=C 1+C 5 * C P 2-C 6 * D P 2$

693

$F N 2=C 2+C 5 * D P 2+C 6 * C P 2$

694

$G N 2=1.0+C 1 * C 5 * C P 2-C 1 * C 6 * D P 2-C 2 * C 5 * D P 2-C 2 * C 6 * C P 2$

695

$H N Z=C 1 * C 5 * O P Z+C 1 * C 6 * C P 2+C 2 * C 5 * C P 2-C 2 * C 6 * D P Z$

696 


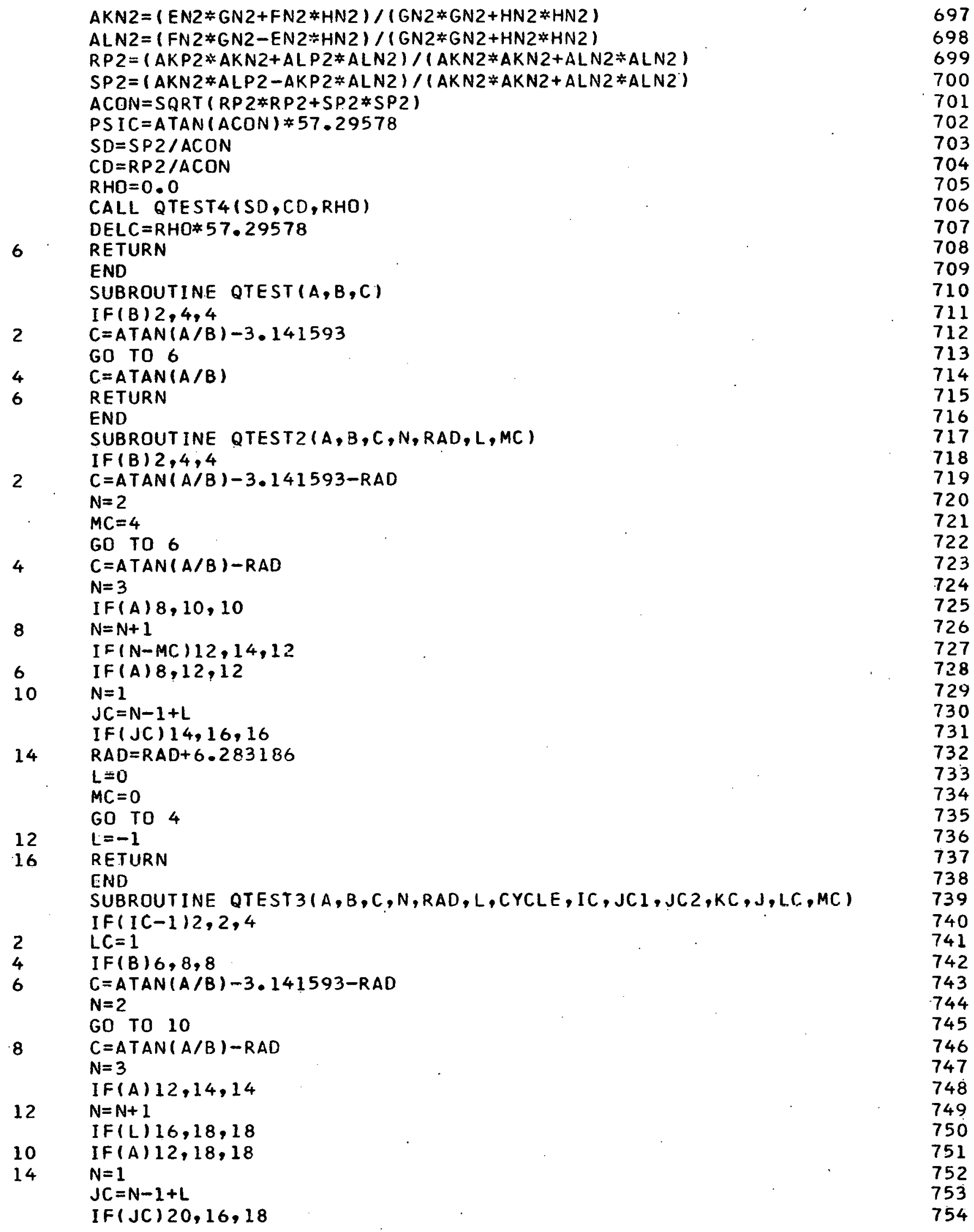




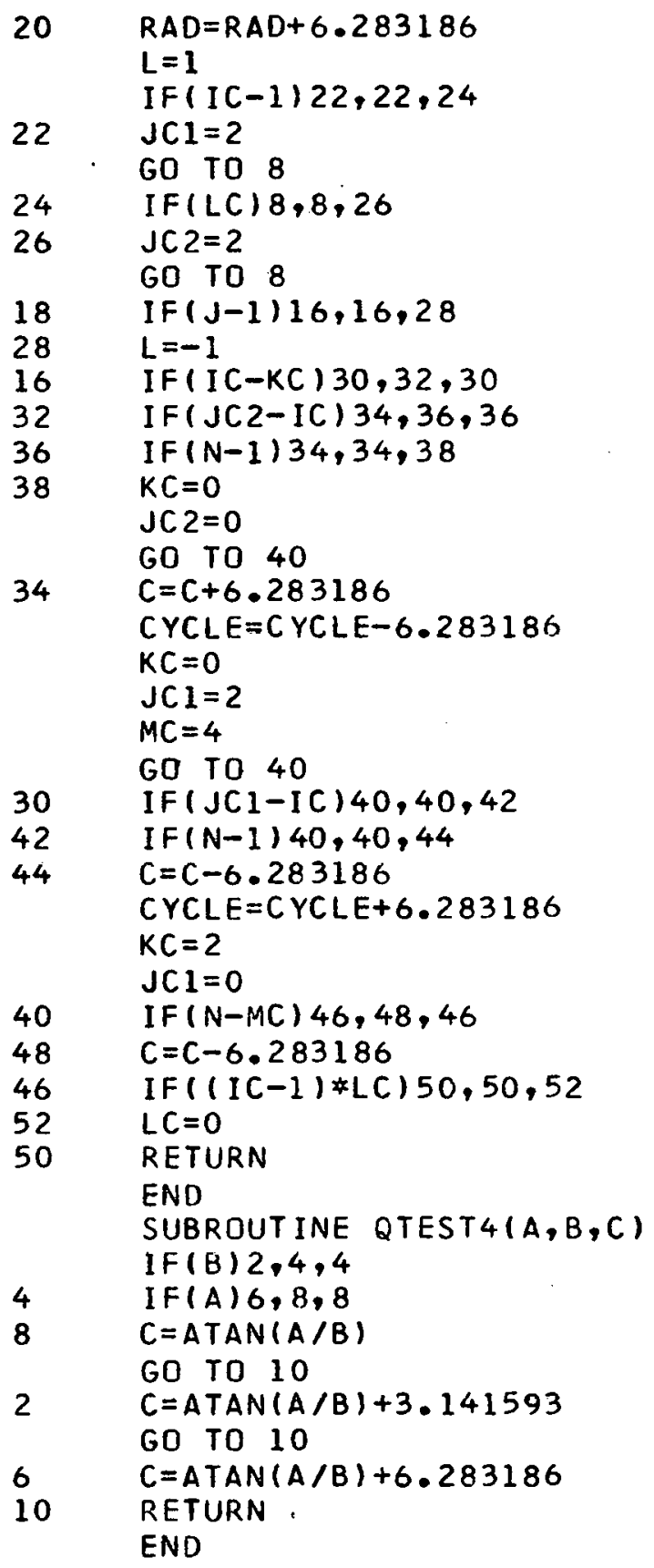


RFP-1392 
APPENDIX B. FORTRAN IV Notation

Appendix B presents an explanation of the essential terms used for the source program. 


\section{RFP-1392}

Note: The index of refraction of a surface film is given by

$\hat{n}_{2}=n_{21}-n_{22} i$, where

$\mathrm{n}_{21}=$ real part of the refractive index.

$\mathrm{n}_{22}=$ imaginary part of the refractive index.

Variable Name Explanation

ANSETS Number of values of $n_{21}$ calculated for a set of psi and delta measurements.

AVE Mean value for the final calculation of $\mathrm{n}_{21}$.

AVF1 Temporary storage location for the beginning mean value calculations of $n_{21}$.

AVE2 Temporary storage location for the maximum value of the $n_{21}$ range.

AVEL Mean value dividing the left side of the reduced $n_{21}$ range.

AVEP Center of the reduced $n_{21}$ range.

AVER Mean value dividing the right side of the reduced $n_{21}$ range.

AVN21 Mean value of $n_{21}$ calculated for the set of psi and delta measurements.

CYCLED Corrects the cycling of angle phi

CYCLES (subroutine subprogram QTEST3).

D2 Real part of film thickness.

D2I Imaginary part of film thickness.

DEL - Optical parameter, delta $(\Delta)$.

DFI.C. Calculated valucs of delta.

DEI.P Optical parameter, delta $\left(\Delta^{\prime}\right)$, of a "clean" surface.

DN21 Increment of $\mathbf{n}_{21}$ used to calculate an array of $n_{21}$. values (subroutine subprogram RANGE).

UN'22 Increment of ṅ $_{22}$ uised to calculate an array of $n_{22}$ values (subroutine subprogram RANGE).

EDEL

Difference between experimental and calculated values of delta $(\delta \Delta)$.
Variable Name

Explanation

EN1

EN21

EN21N Minimum value of the $n_{21}$ range.

EN21X Maximum value of the $n_{21}$ range.

EN22 Value of $n_{22}$.

EN22N : Minimum value of the $n_{22}$ range.

EN22X Maximum value of the n 2.2 range.

EN3 Subroutine subprogram for calculating the refractive index of the substrate, $\hat{n}_{3}=n_{31}-n_{32} i$.

EN31 Real part of the refractive index of the substrate $\left(n_{31}\right)$.

EN32 Imaginary part of the refractive index of the substrate $\left(\mathrm{n}_{3 i}\right.$.).

EPSI Difference between experimental and calculated values of psi $(\delta \psi)$.

ERROR $\quad \sqrt{(\delta \psi)^{2}+(\delta \Delta)^{2}}$

ESUM $\sqrt{(\delta \psi)^{2}+(\delta \Delta)^{2}}$

Index variable for contrulling the minimum and maximum values of the $n_{21}$ range.

ICOUNT Number of values of $n_{21}$ calculated for a set of psi and delta measurements.

IDIAG Code numbers for the resulting $n_{21}$ calculatiotions for psi and delta.

IPATH Variable name for testing for a solution using the minimum and maximum values of the $n_{21}$ range.

IPICK Variable name segmenting the main program.

ISHIFT Variable name segmenting the subroutine subprogram RID2. 
Variable Name

Explanation

ITOL Variable name for the execution of the tolerance level used to determine $n_{21}$ for psi and delta.

IVARI Control number used to compute and compare error for $n_{21}$.

J

J21 Control number for the $\mathrm{n}_{21}$ values in a data set.

$\left.\begin{array}{l}\text { JC1D } \\ \text { JC1S } \\ \text { JC2D } \\ \text { JC2S }\end{array}\right\}$

J

JVARI Control number used to compute and compare error for $\mathrm{n}_{21}$.

$\mathrm{K}$ Index variable for values of $\mathrm{n}_{\mathbf{2 2}}$.

K22 Control number to determine $\mathrm{n}_{22}$.

KCD Control numbers for the cycling

KCS $\}$ of angle phi (subroutine subprogram

QTEST3).

KK Control number for the output device.

KVARI Control number used to compute and compare error for $n_{21}$.

L Index variable for the error term $\epsilon$. Index variable for the final calculation of $n_{21}$.

LABEL Data set identification.

LCD Control numbers for the cycling of angle

LCS phi (subroutine subprogram QTEST3).

$\left.\begin{array}{l}\text { LD } \\ \text { LS }\end{array}\right\} \begin{aligned} & \text { Control numbers for determining the } \\ & \text { quadrant for angle phi (subroutine } \\ & \text { subprogram QTEST2 and QTEST3). }\end{aligned}$

LVARI Control number used to compute and compare error for $n_{21}$.
Variable Name

Explanation

MCD Control numbers for determining the MCS quadrant for angle phi (subroutine subprogram QTEST2 and QTEST 3).

MVARI Control number used to compute and compare error for $n_{21}$.

N21 Number of $n_{21}$ values computed for a range of $n_{21}$.

N22

Number of $n_{22}$ values computed for a range of $n_{22}$.

NQ Quadrant for the angle phi.

NSETS Number of psi and delta measurements.

NTEST Variable name limiting the cycling for $\mathrm{n}_{21}$.

NTOL Control number determining the error for $\mathrm{n}_{21}$.

NUMBER Number of data sets to be processed.

OPN21 Value of $n_{21}$ determined for a psi and delta measurement. Value of $n_{21}$.

PHI $\quad$ Angle of incidence $\left(\phi_{1}\right)$.

PSI Optical parameter, psi $(\psi)$.

PSIC Calculated values of psi.

PSIP Optical parameter, psi $\left(\psi^{\prime}\right)$, of a "clean" surface.

QTEST Subroutine subprogram for correcting the quadrant of angle phi.

QTEST2 Subroutine subprogram for correcting the quadrant of angle phi and controlling the cycling of angle phi.

QTEST3 Subroutine subprogram for correcting the quadrant of angle phi, controlling the cycling of angle phi and maintaining the simultaneous theoretical cycling of the angle phi for minimum and maximum values of $n_{21}$, for each psi and delta niiéasuirimenent. 
RFP-1392

Variable Name

Explanation

QTEST4

Subroutine subprogram for selecting the quadrant for the optical parameter, delta $(\Delta)$

RADD Control numbers for the cycling of angle RADS phi (subroutine subprogram QTEST2 and QTEST3).

RANGE Subroutine subprogram for calculating the number of $n_{22}$ values and the number of $\because \therefore n_{21}$ values from their respective ranges.

RID2 Subroutine subprogram for calculating film thicknesses and the psi $(\psi)$ and delta $(\Delta)$ optical parameterș.
Variable Name $\cdot: \quad$ 'Explanation

SIGMA Standard error for the mean $n_{21}$ value calculated for a set of psi and delta meàsüirèments.

SUM1 Variable names used to compute standard SUM2 $\}$ error.

TOL

Tolerance level given to determine $n_{21}$.

WAVF, Wavelength $(\lambda)$ nf the light beam. 